\title{
Investigation of Train-induced Vibration and Noise from a Steel-concrete Composite Railway Bridge Using a Hybrid Finite Element-Statistical Energy Analysis Method
}

\author{
Quanmin Liu ${ }^{\mathrm{a},}{ }^{,}$, David J Thompson ${ }^{\mathrm{b}}$, Peipei Xu ${ }^{\mathrm{a}}$, Qingsong Feng ${ }^{\mathrm{a}}$, Xiaozhen $\mathrm{Li}^{\mathrm{c}}$ \\ ${ }^{a}$ MOE Engineering Research Centre of Railway Environmental Vibration and Noise, East China Jiaotong University, Nanchang \\ 330013, China \\ ${ }^{b}$ Institute of Sound and Vibration Research, University of Southampton, Southampton SO17 1BJ, UK \\ ${ }^{c}$ Department of Bridge Engineering, Southwest Jiaotong University, Chengdu 610031, China
}

Abstract: In this study a hybrid finite element-statistical energy analysis (FE-SEA) method is used to investigate the structure-borne noise of a steel-concrete composite railway bridge. The rail is represented by an infinite Timoshenko beam connected to the sleepers which are regarded as finite Timoshenko beams supported in ballast. The fasteners and ballast are simplified as a series of springs with complex stiffness. This model allows the receptance of the track to be determined. The wheel-rail forces are computed in the frequency domain from the contact-filtered roughness and the receptances of the wheel, track, and contact. The forces transmitted to the bridge are determined by substituting the wheel-rail forces into the equation of motion for the track. This model could also be applied to a slab track mounted on a bridge. A hybrid FE-SEA method is introduced in which FE is used to model the concrete deck and SEA is used to model the steel girders. This enables the computation of the vibration and noise of the composite railway bridge. The proposed method is verified by comparing its predictions with field measurements. The structure-borne noise level of the bridge is found to increase with train speed $v$ by approximately $20 \lg (v)$. It is shown that the adjacent spans in a multi-span bridge can be ignored in deriving the bridge-borne noise at receiver points in the middle of the main span, provided that the distance to the track centreline is less than 0.3 times the length of the main span.

Key words: composite bridge; structure-borne noise; hybrid FE-SEA method; sound contribution; geometrical attenuation 


\section{Introduction}

Due to increases in the train speed and density of railway networks, considerable numbers of complaints arise from residents living close to the line about the train-induced vibration and noise. Long-term exposure to high levels of vibration and noise can adversely affect people's quality of life and may have long-term effects on health. In China, the high-speed railway network extends over $31,000 \mathrm{~km}$, much of which is elevated. However, in general bridge sections generate more noise than plain tracks at ground level, typically by around $5 \mathrm{~dB}$ for concrete bridges, and $10 \mathrm{~dB}$ on average for steel bridges [1]. Investigations into the structure-borne noise of railway bridges are therefore of great significance in route planning, bridge design, and mitigation of vibration and noise.

In the last few decades, many studies have been carried out into the noise emitted by concrete bridges and viaducts, mainly utilizing the finite element method (FEM) to compute the vibration and the boundary element method (BEM) to calculate the acoustic radiation. Crockett and Pyke [2] computed the vibration of a viaduct induced by the wheel-rail interaction by employing FEM to model the structure, track, and vehicle, and then obtained an estimate of the noise radiated to the wayside from the bridge vibration, neglecting the directivity. Wu and Liu [3] used a two-stage approach. They first considered the bridge to be rigid in order to compute the fastener forces from their stiffness and relative displacement; the bridge vibration was then derived in the frequency domain using FEM by taking the fastener forces as the excitation. The structure-borne noise from the bridge was estimated by using an analytical expression for the acoustic power. Li et al. [4] adopted FEM to resolve the transient train-track-bridge coupled vibration in the time domain, using a modal superposition method. Three-dimensional (3D) BEM was then utilized to determine the low-frequency sound pressure emanating from the viaduct by multiplying the modal coordinate spectrum with the modal acoustic transfer vectors. The method was applied to a U-shaped concrete viaduct. Zhang et al. [5] derived the vibration of a concrete box beam based on a coupled analysis of 
the train, track and bridge in the time domain, and determined the acoustic radiation of the viaduct by using 3D BEM.

However, fully 3D FEM and BEM models are quite time-consuming in the prediction of the vibration and noise of bridges. In order to improve the computational efficiency, Li et al. [6] adopted 2.5-dimensional (2.5D) BEM to study the structure-borne noise of a U-shaped viaduct. The applicability of two-dimensional (2D) infinite elements coupled to acoustic FEM for the structure-borne noise calculation of a U-shaped viaduct in the frequency domain was investigated in [7]. Based on numerical computations of the train-track-bridge coupled vibration in the time domain, Song et al. studied the structure-borne noise of a U-shaped viaduct by employing 2.5D BEM [8] and a 2.5D infinite element method [9]. A 2.5D FEM was also employed by Song et al. to study the medium- and high-frequency vibration characteristics of a box-girder bridge [10].

Steel-concrete composite bridges, composed of steel beams supporting a concrete deck, are often used for railway bridges of small and medium span length [11]. Such bridges were built with direct rail fastening systems for many years, but most modern composite railway bridges are fitted with ballasted or slab track. Steel bridges and steel-concrete composite bridges generally produce more structure-borne noise than fully-concrete bridges. As the structure-borne noise from a steel or composite bridge can be relevant up to $1000 \mathrm{~Hz}$, and as these structures have a very large number of vibration modes in this frequency range, a huge computational cost would be involved in the noise calculation of the whole bridge using 3D FEM and BEM. Therefore, previous studies using these methods have focused on a small section of the steel bridge. Augusztinovicz et al. [12] calculated the vibration of a steel road bridge using FEM based on an estimated force input to the deck plate due to a tram; they then derived the structure-borne noise by using BEM. Statistical energy analysis (SEA) and experimental transfer functions were also used. Alten and Flesch [13] studied the vibration of a steel truss bridge section by using FEM and investigated various design options in terms of their vibration; comparisons were made with measured noise. 
To obtain the acoustic radiation of the whole bridge, Remington and Wittig [14] used an approach based on SEA. They computed the vertical rail velocity in the frequency domain by using the wheel and rail impedances and roughness spectra. The mean-square bridge velocity was derived from the vibration ratios between the rail, tie, and girder deduced from the power balance equations of SEA by simplifying the girder as a single degree-of-freedom (DOF) system; then the acoustic power of the girder was obtained through an analytical expression. Janssens and Thompson [15] used a strongly-coupled SEA model for a steel bridge. They calculated the power input to the bridge based on the bridge mobility, equivalent fastener stiffness, and measured rail vibration. The mean square velocity of each bridge plate was obtained through the strongly-coupled assumption and the sound radiation was calculated using analytical formulae for the radiation efficiency of plates. Based on this approach, Bewes et al. [16] improved the rail-bridge coupling calculation below the decoupling frequency and modified the high-frequency mobility of the bridge by considering in-plane deformation of the cross-section. The method was also applied to a steel-concrete composite bridge in [17]. Poisson and Margiocchi [18] studied the sound and vibration characteristics of a steel truss bridge by adopting FEM below $200 \mathrm{~Hz}$ and SEA above this frequency. They identified that the rail was a major source of noise and investigated the noise reduction effect of rail dampers experimentally. Li et al. [19] discussed the vibration and noise characteristics of a composite railway bridge by combining a coupled train-track-bridge model in the time domain with SEA in the frequency domain.

In an alternative approach, Ouelaa et al. [20] employed the modal superposition method to compute the acceleration of a steel bridge, and the acoustic pressure was determined by representing the bridge as a set of monopoles. Michishita et al. [21] analysed the noise reduction due to surface absorption on a steel plate girder, assuming the plate girder to be a line source and the concrete deck to be an infinite rigid reflective surface based on a simplified 2D model. Xie et al. [22] discretized the bridge deck into a large number of small patches, neglecting the 
acoustic-structure interaction, and derived the low-frequency acoustic radiation of a steel highway bridge.

The FEM/BEM approach has a good accuracy in assessing the vibration and noise of bridges at low frequency, but as the required element size decreases with increasing frequency, it becomes impractical to use it for higher frequencies. The SEA method is suitable for computing the vibration and noise at high frequencies, but at low frequencies, its calculation accuracy is poor because of the low modal density. The noise from the concrete decks of steel-concrete composite bridges is mostly concentrated below $300 \mathrm{~Hz}$ [19] where there is a low modal density, suggesting that FEM can be used to obtain the vibration of such components. The noise of the steel beams can be important up to $1000 \mathrm{~Hz}$ where the number of modes is sufficiently high to justify the use of the SEA method. Such a structure is therefore suitable for the hybrid FE-SEA method, which allows stiff components to be modelled using FEM and more flexible components to be modelled using SEA [23]. A good balance between the accuracy and expense can be achieved in the vibration and noise calculation of composite bridges through utilizing this hybrid FE-SEA method.

In this study the hybrid FE-SEA method is used to investigate the structure-borne noise of a steel-concrete composite bridge. First, a discretely supported track model is established in the frequency domain to compute the forces transmitted to the bridge. This uses an infinite Timoshenko beam to model the rail, attached to a series of equivalent supports with a complex stiffness representing the fasteners connected to the sleepers which are represented by finite Timoshenko beams supported in ballast. This model is used to determine the receptance of the track, which is then used together with the wheel and contact receptances in deriving the wheel-rail interaction forces from the moving roughness model. The forces transmitted to the bridge are obtained by substituting the wheel-rail force into the equations of motion for the track. The above procedure can also be applied to a slab track mounted on a bridge by representing the slab by a finite Timoshenko beam supported by distributed springs and dampers. Subsequently, the hybrid FE-SEA method is 
employed to calculate the vibration and noise of the composite bridge, using FE to model the concrete deck and SEA to model the steel beam. The approach is verified by comparing the numerical results with on-site measured data. In addition, formulae are derived for the bridge-borne noise in terms of the train speed and distance for use in the environmental assessments of railways.

\section{Calculation method for forces transmitted to bridge}

The wheel-rail system is excited by the roughness of the wheel tread and rail surface [24], as well as by parametric excitation arising from the periodically varying stiffness of the track [25]. Parametric excitation may be included in terms of an equivalent roughness excitation. It is generally of less relevance for lower values of support stiffness [1] and is neglected here. Since the train speed of current railway systems is considerably lower than the propagation velocity of the vibration waves in the periodically supported rail, the wheel-rail interaction can be obtained with the moving roughness model. This is based on the assumption that the roughness is 'pulled' between the wheel and the rail at the train passing speed. However, the position of the wheels relative to the track is based on the actual situation at one particular time. Then all $n_{\mathrm{w}}$ vertical wheel-rail forces acting on one rail at frequency $\omega$ are given as follows [1]

$$
\mathbf{F}_{\mathrm{wr}}=-\left(\boldsymbol{\beta}_{\mathrm{w}}+\boldsymbol{\beta}_{\mathrm{c}}+\boldsymbol{\beta}_{\mathrm{t}}\right)^{-1} \boldsymbol{\Delta}
$$

where $\Delta$ is a vector containing the vertical roughness amplitude at the $n_{\mathrm{w}}$ wheel-rail contacts on one

rail; $\boldsymbol{\beta}_{\mathrm{w}}, \boldsymbol{\beta}_{\mathrm{t}}$, and $\boldsymbol{\beta}_{\mathrm{c}}$ are the $n_{\mathrm{w}} \times n_{\mathrm{w}}$ receptance matrices of the wheels, track, and wheel-rail contact, respectively and $n_{\mathrm{w}}$ is the number of wheels on the rail.

\subsection{Assumptions}

As well as the noise from the bridge, the noise from a train on a bridge consists of rolling noise and (at high speed) aerodynamic noise. A number of techniques are available to control the rolling 
noise, including rail dampers [18] and sound barriers [26]. Aerodynamic noise is the dominant source of railway noise above about $300 \mathrm{~km} / \mathrm{h}$, control measures for which include shape optimization of high-speed trains and added fairings for the bogie and pantograph [27]. This study focuses only on the structure-borne noise of bridges.

The lower-limit frequency of human hearing is about $20 \mathrm{~Hz}$. The bridge-borne noise of composite bridges occurs mainly below about $1000 \mathrm{~Hz}$. Allowing for the width of 1/3 octave bands, and to extend the upper limit to the $1600 \mathrm{~Hz}$ band, the selected frequency range for analysis in this study is from 17.8 to $1780 \mathrm{~Hz}$.

A vertical model is established based on a single rail, i.e. half-width track and vehicles, to compute the forces transmitted to the bridge. Then the forces from both rails will be applied to the bridge in the calculation of the train-induced vibration and noise.

\subsection{Wheel receptance}

The natural frequency of the primary suspension of rail vehicles is typically around $10 \mathrm{~Hz}$ and that of the secondary suspension is approximately $1 \mathrm{~Hz}$. Thus, in the frequency range of interest the wheels can be treated as independent, neglecting coupling through the bogie and car body. The primary suspension is retained together with the bogie mass. Its receptance can be expressed as [28]

$$
\beta_{\mathrm{w}}=\frac{k_{1}+\mathrm{i} \omega c_{1}-m_{\mathrm{b}} \omega^{2}}{m_{\mathrm{w}} m_{\mathrm{b}} \omega^{4}-\left(k_{1}+\mathrm{i} \omega c_{1}\right)\left(m_{\mathrm{w}}+m_{\mathrm{b}}\right) \omega^{2}}+\frac{1}{k_{\mathrm{m}}\left(1+\mathrm{i} \eta_{\mathrm{m}}\right)}
$$

where $\omega$ is the angular frequency; $m_{\mathrm{b}}$ and $m_{\mathrm{w}}$ represent the masses of a quarter of the bogie and half of the wheelset, respectively; $k_{1}$ and $c_{1}$ indicate the stiffness and damping of the primary suspension, and $\mathrm{i}=\sqrt{-1} . k_{\mathrm{m}}$ is the modal stiffness associated with high frequency modes in the wheel receptance; $\eta_{\mathrm{m}}$ is the loss factor corresponding to $k_{\mathrm{m}}$. 
The receptance matrix of all wheels acting on the rail can be written as

$$
\boldsymbol{\beta}_{\mathrm{w}}=\operatorname{diag}\left\{\begin{array}{llll}
\beta_{\mathrm{w}} & \beta_{\mathrm{w}} & \cdots & \beta_{\mathrm{w}}
\end{array}\right\}_{n_{\mathrm{w}}}
$$

\subsection{Track receptance}

The vertical dynamic stiffness of a bridge is much higher than that of the track. From [29], it is found that the receptance of the track does not change significantly whether the bridge is considered or not. In computing the track receptances the bridge is therefore simplified as a rigid foundation below the track; the rail is discretely supported by the fastener-sleeper-ballast system, as shown in Fig. 1. An infinite Timoshenko beam is used to model the rail whereas the sleepers are represented as finite uniform Timoshenko beams supported in the ballast. The rail fasteners are simplified as discrete elastic supports, represented by a stiffness and a damping loss factor. The ballast is represented by a continuous layer of stiffness and viscous damping beneath each sleeper.

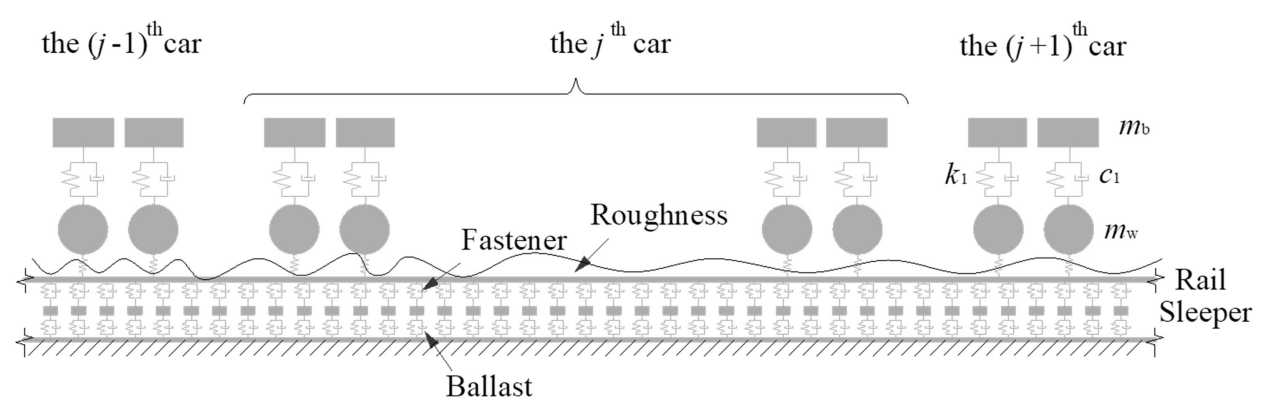

Fig. 1. Train and track model.

The displacement of the rail at an arbitrary longitudinal position $x$ is

$$
z_{\mathrm{r}}(x)=\sum_{j=1}^{n_{\mathrm{w}}} \beta_{\mathrm{r}}\left(x, x_{j}\right) P_{j}-\sum_{k=1}^{n_{\mathrm{f}}} \beta_{\mathrm{r}}\left(x, x_{k}\right) F_{\mathrm{f}, k}
$$

where $\beta_{\mathrm{r}}\left(x, x_{j}\right)$ depicts the displacement of the free rail at $x$ when a unit force is applied at $x_{j}, P_{j}$ is the $j^{\text {th }}$ wheel-rail force, $F_{\mathrm{f}, k}$ is the force applied to the rail by the fastener at the $k^{\text {th }}$ support at $x_{k}$, and $n_{\mathrm{f}}$ represents the number of fasteners considered under one rail.

In most models of bridge noise, the rail has usually been represented as an Euler-Bernoulli beam. 
This model is suitable for describing the vertical dynamic response of the track for frequencies up to about $500 \mathrm{~Hz}$ [1]. For higher frequencies a model based on a Timoshenko beam, which includes shear deformation and rotational inertia, can be used for rail vibration in the vertical direction up to $2500 \mathrm{~Hz}$ [30]. This is used in the current study. The transfer receptance of an infinite Timoshenko beam is given as [31]

$$
\beta_{\mathrm{r}}\left(x_{1}, x_{2}\right)=u_{1} \exp \left(-\mathrm{i} k_{1}\left|x_{1}-x_{2}\right|\right)+u_{2} \exp \left(-k_{2}\left|x_{1}-x_{2}\right|\right)
$$

where

$$
\begin{gathered}
u_{1}=\frac{\mathrm{i}}{2 E_{\mathrm{r}} I_{\mathrm{r}} G_{\mathrm{r}} A_{\mathrm{r}} \kappa\left(1+\mathrm{i} \eta_{\mathrm{r}}\right)^{2}} \frac{\rho_{\mathrm{r}} I_{\mathrm{r}} \omega^{2}-G_{\mathrm{r}} A_{\mathrm{r}} \kappa\left(1+\mathrm{i} \eta_{\mathrm{r}}\right)-E_{\mathrm{r}} I_{\mathrm{r}} k_{1}^{2}\left(1+\mathrm{i} \eta_{\mathrm{r}}\right)}{k_{1}\left(k_{1}^{2}+k_{2}^{2}\right)} \\
u_{2}=\frac{1}{2 E_{\mathrm{r}} I_{\mathrm{r}} G_{\mathrm{r}} A_{\mathrm{r}} \kappa\left(1+\mathrm{i} \eta_{\mathrm{r}}\right)^{2}} \frac{\rho_{\mathrm{r}} I_{\mathrm{r}} \omega^{2}-G_{\mathrm{r}} A_{\mathrm{r}} \kappa\left(1+\mathrm{i} \eta_{\mathrm{r}}\right)-E_{\mathrm{r}} I_{\mathrm{r}} k_{2}^{2}\left(1+\mathrm{i} \eta_{\mathrm{r}}\right)}{k_{2}\left(k_{1}^{2}+k_{2}^{2}\right)} \\
k_{1,2}=\left(\frac{\omega}{\sqrt{2}}\right)\left\{ \pm\left(\frac{\rho_{\mathrm{r}}}{E_{\mathrm{r}}\left(1+\mathrm{i} \eta_{\mathrm{r}}\right)}+\frac{\rho_{\mathrm{r}}}{G_{\mathrm{r}} \kappa\left(1+\mathrm{i} \eta_{\mathrm{r}}\right)}\right)+\left[\left(\frac{\rho_{\mathrm{r}}}{E_{\mathrm{r}}\left(1+\mathrm{i} \eta_{\mathrm{r}}\right)}-\frac{\rho_{\mathrm{r}}}{G_{\mathrm{r}} \kappa\left(1+\mathrm{i} \eta_{\mathrm{r}}\right)}\right)^{2}+\frac{4 \rho_{\mathrm{r}} A_{\mathrm{r}}}{E_{\mathrm{r}} I_{\mathrm{r}} \omega^{2}\left(1+\mathrm{i} \eta_{\mathrm{r}}\right)}\right]^{1 / 2}\right\}^{1 / 2}
\end{gathered}
$$

where $E_{\mathrm{r}}$ and $G_{\mathrm{r}}$ represent the Young's modulus and shear modulus of the rail, $A_{\mathrm{r}}$ and $I_{\mathrm{r}}$ indicate the area and second moment of area of the rail cross section, $\rho_{\mathrm{r}}$ and $\eta_{\mathrm{r}}$ depict rail density and loss factor, and $\kappa$ is the Timoshenko shear coefficient depending on the cross-section shape, with $\kappa<1$.

The displacement of the $k^{\text {th }}$ sleeper is given by

$$
z_{\mathrm{s}}\left(x_{k}\right)=\beta_{\mathrm{s}} F_{\mathrm{f}, k}
$$

where $\beta_{\mathrm{s}}$ is the point receptance of the sleeper on an elastic foundation based on [1].

The fastener force under the rail is obtained from [32]

$$
F_{\mathrm{f}, k}=k_{\mathrm{f}}\left(1+\mathrm{i} \eta_{\mathrm{f}}\right)\left[z_{\mathrm{r}}\left(x_{k}\right)-z_{\mathrm{s}}\left(x_{k}\right)\right]
$$

where $k_{\mathrm{f}}$ is the real part of the complex stiffness of the fastener and $\eta_{\mathrm{f}}$ is the corresponding damping loss factor. 
Substituting Eq. (10) into Eqs. (4) and (9), a matrix form is obtained as

$$
\boldsymbol{\beta} \mathbf{z}=\mathbf{P}
$$

where $\boldsymbol{\beta}$ is a matrix composed of the rail and sleeper receptances and the fastener stiffness. The displacement vector is expressed as

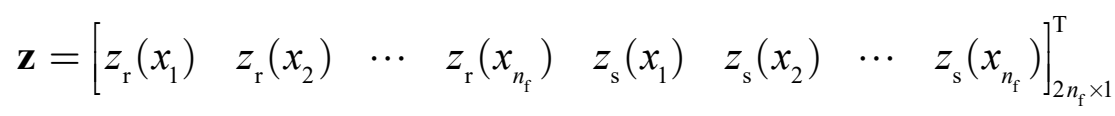

The vector $\mathbf{P}$ is given by

$$
\mathbf{P}=\left[\sum_{j=1}^{n_{\mathrm{w}}} \beta_{\mathrm{r}}\left(x_{1}, x_{j}\right) P_{j} \quad \sum_{j=1}^{n_{\mathrm{w}}} \beta_{\mathrm{r}}\left(x_{2}, x_{j}\right) P_{j} \quad \cdots \quad \sum_{j=1}^{n_{\mathrm{w}}} \beta_{\mathrm{r}}\left(x_{n_{\mathrm{f}}}, x_{j}\right) P_{j} \quad 0 \quad 00 \quad \cdots \quad\right]_{2 n_{\mathrm{f}} \times 1}^{\mathrm{T}}
$$

Assuming that there is a unit harmonic force $P_{j}=\exp (\mathrm{i} \omega t)$ acting on an arbitrary position of the rail, the displacement vector can be determined by solving Eq. (11) if the receptances of the free rail $\beta_{\mathrm{r}}\left(x, x_{j}\right)$ and flexible sleeper $\beta_{\mathrm{s}}$ are known. Then all fastener forces $F_{\mathrm{f}, k}$ can be obtained through Eq. (10) and the track receptance at an arbitrary point of the rail can be determined by substituting a single unit excitation force and all the corresponding fastener forces into Eq. (4). The receptance matrix of the track at the wheel positions follows

$$
\boldsymbol{\beta}_{\mathrm{t}}=\left[\begin{array}{cccc}
\beta_{11}^{\mathrm{t}} & \beta_{12}^{\mathrm{t}} & \cdots & \beta_{1 n_{\mathrm{w}}}^{\mathrm{t}} \\
& \beta_{22}^{\mathrm{t}} & \cdots & \beta_{2 n_{\mathrm{w}}}^{\mathrm{t}} \\
& \text { Symmetric } & \ddots & \vdots \\
& & & \beta_{n_{\mathrm{w}} n_{\mathrm{w}}}^{\mathrm{t}}
\end{array}\right]
$$

where $\beta_{p q}^{\mathrm{t}}$ is the rail displacement at the $p^{\text {th }}$ wheel when a unit force is applied on the rail at the position of the $q^{\text {th }}$ wheel.

\subsection{Wheel-rail contact receptance}

The contact receptance matrix can be written as 


$$
\boldsymbol{\beta}_{\mathrm{c}}=\operatorname{diag}\left\{\begin{array}{llll}
\beta_{\mathrm{c}} & \beta_{\mathrm{c}} & \cdots & \beta_{\mathrm{c}}
\end{array}\right\}_{n_{\mathrm{w}} \times n_{\mathrm{w}}}
$$

where $\beta_{\mathrm{c}}=1 / k_{\mathrm{H}}$, in which $k_{\mathrm{H}}$ is the linearised Hertzian contact stiffness that depends on the wheel radius, rail head radius of curvature and axle load [1].

\subsection{Forces transmitted to bridge}

Generally, the track vertical irregularity profile can be regarded as a stationary ergodic Gaussian random process apart from areas with turnouts, crossings or local track deterioration [33]. Assuming that the same irregularity excites each wheel-rail contact apart from a time lag, the roughness vector of four contact points under the $m^{\text {th }}$ vehicle can be expressed as

$$
\begin{aligned}
\Delta_{m}(\omega)= & \left\{\exp \left[\mathrm{i} \omega(m-1) l_{\mathrm{c}} / v\right] \exp \left[\mathrm{i} \omega\left[(m-1) l_{\mathrm{c}}+2 l_{\mathrm{w}}\right] / v\right]\right. \\
& \left.\exp \left[\mathrm{i} \omega\left[(m-1) l_{\mathrm{c}}+2 l_{\mathrm{b}}\right] / v\right] \exp \left[\mathrm{i} \omega\left[(m-1) l_{\mathrm{c}}+2 l_{\mathrm{w}}+2 l_{\mathrm{b}}\right] / v\right]\right\}^{\mathrm{T}} \Delta(\omega)
\end{aligned}
$$

where $l_{\mathrm{c}}$ is the vehicle length, $l_{\mathrm{b}}$ represents half the distance between the bogie centres, $l_{\mathrm{w}}$ indicates half the wheelbase of the bogie, $v$ is the train speed and $\Delta$ is the roughness amplitude at frequency $\omega$. The roughness vector at all contact points is formed by assembling $\Delta_{m}(\omega)$ for all vehicles.

If the wheel, track, and contact receptances, as well as the roughness spectrum are known, all wheel-rail forces can be derived from Eq. (1). Then the vector of rail and sleeper displacements can be obtained by substituting the computed wheel-rail forces into Eq. (11). Furthermore, to determine the forces transmitted to the bridge, it is assumed that the ballast beneath a half-sleeper can be replaced by a single spring and damper. The forces transmitted to the bridge by each sleeper of the half-width track, can be derived from

$$
F_{\mathrm{b}, k}=\left(K_{\mathrm{b}}+\mathrm{i} \omega C_{\mathrm{b}}\right) z_{\mathrm{s}}\left(x_{k}\right)
$$

where $K_{\mathrm{b}}$ and $C_{\mathrm{b}}$ are the stiffness and viscous damping of ballast beneath each half-sleeper.

This model can also be used to calculate the forces transmitted to a viaduct fitted with a normal 
slab track or a floating slab track. The rail is still modelled by an infinite Timoshenko beam and the slab is represented by finite uniform Timoshenko beams supported on the bearing layer. The rail fasteners are simplified as discrete elastic supports, represented by a stiffness and a damping loss factor. The bearing layer is represented by distributed springs and viscous dampers.

\section{Hybrid FE-SEA method to compute the vibration and noise of composite bridges}

A typical composite railway bridge consists of a concrete deck with I-shaped or box steel girders beneath it. This study aims to use a hybrid FE-SEA approach to characterize the structure-borne noise emitted from a composite railway bridge, to achieve a balance between the computing efficiency and accuracy. Moreover, if distinct models are used for different frequency ranges, this could lead to a discontinuity at the dividing frequency between them; the hybrid approach can avoid this. The excitation of the hybrid FE-SEA model is taken as the set of forces beneath each sleeper calculated using the method described in the previous section. The equations of motion are presented separately for the FE, SEA, and FE-SEA coupled parts.

\subsection{FE equations of motion}

For a system modelled using FE, the equations of motion governing the amplitudes $\mathbf{u}$ at the node points can be obtained from Lagrange's equations and have the well-known form

$$
\left[-\omega^{2} \mathbf{M}+\mathrm{i} \omega \mathbf{C}+\mathbf{K}\right] \mathbf{u}=\mathbf{D}_{\mathrm{d}} \mathbf{u}=\mathbf{f}
$$

where $\mathbf{M}, \mathbf{C}$, and $\mathbf{K}$ are the mass, damping, and stiffness matrices, respectively; $\mathbf{D}_{\mathrm{d}}$ is the dynamic stiffness matrix; $\mathbf{u}$ and $\mathbf{f}$ indicate the vectors of the amplitudes of the nodal displacements and external forces, respectively.

\subsection{SEA equations}


By applying SEA to predict the average vibration in various frequency bands generated by a complex structure, the bridge should be divided into structural subsystems according to similar modal groups and boundary conditions. If a subsystem has a sufficient number of modes in the frequency bands of interest, modal energy equipartition can be assumed. Additionally, it is also assumed that the energy is uniformly distributed within each subsystem. The power balance equations are derived by relating the stored, dissipated, and transmitted energies between subsystems. Assuming a linear system consisting of $N_{1}$ coupled subsystems, the power balance equation of the $j^{\text {th }}$ subsystem is expressed as [34]

$$
\omega \eta_{j} E_{j}+\sum_{\substack{k=1 \\ k \neq j}}^{N_{1}}\left(\omega \eta_{j k} E_{j}-\omega \eta_{k j} E_{k}\right)=P_{\mathrm{in}, j}
$$

where $\eta_{j}$ represents the damping loss factor of the $j^{\text {th }}$ subsystem, $\eta_{j k}$ denotes the coupling loss factor from the $j^{\text {th }}$ subsystem to the $k^{\text {th }}$ subsystem, $P_{\mathrm{in}, j}$ represents the power input to the $j^{\text {th }}$ subsystem, and $E_{j}$ is the vibrational energy of the $j^{\text {th }}$ subsystem. Expressions for the coupling loss factors are given, for example, in [35].

\subsection{FE-SEA coupling}

Based on the work of Langley and Shorter [36-38], this section summarizes the equations and procedures for using the hybrid FE-SEA approach to calculate the vibration and noise of composite bridges. Components with a low modal density are modelled by FE and regarded as deterministic, and other components are represented by SEA subsystems. The complete set of deterministic components can be described by a set of displacements $\mathbf{u}$, while the statistical components are represented by a set of energies $\mathbf{E}$. The set of deterministic components is considered as the master system, while each of the statistical components is taken as a subsidiary subsystem.

The equations of motion of the master system at a specific frequency $\omega$ can be written as

$$
\mathbf{D}_{\mathrm{tot}} \mathbf{u}=\mathbf{f}_{\mathrm{ext}}+\sum_{k=1}^{N_{2}} \mathbf{f}_{\mathrm{rev}}^{(k)}
$$


where $\mathbf{f}_{\text {ext }}$ contains the external forces applied directly to the master system, $N_{2}$ represents the number of SEA subsystems, the reverberant force $\mathbf{f}_{\mathrm{rev}}^{(k)}$ describes the force on the connection arising from the reverberant field in the $k^{\text {th }}$ subsystem, and the total dynamic stiffness matrix $\mathbf{D}_{\text {tot }}$ is found by adding the dynamic stiffness matrix of the FE components $\mathbf{D}_{\mathrm{d}}$ to the direct field dynamic stiffness matrix from each subsystem $\mathbf{D}_{\mathrm{dir}}^{(k)}$.

$$
\mathbf{D}_{\mathrm{tot}}=\mathbf{D}_{\mathrm{d}}+\sum_{k=1}^{N_{2}} \mathbf{D}_{\mathrm{dir}}^{(k)}
$$

According to Eq. (20), the vector containing the nodal displacements of FE components allowing for coupling with SEA subsystems is given by

$$
\mathbf{u}=\mathbf{D}_{\text {tot }}^{-1}\left(\mathbf{f}_{\mathrm{ext}}+\sum_{k=1}^{N_{2}} \mathbf{f}_{\mathrm{rev}}^{(k)}\right)
$$

As described by Shorter and Langley [36], a diffuse field reciprocity relation applies to the coupling between these two types of components. This relates the cross-spectrum of the forces at the boundary of a statistical component to the vibrational energy level of the component. The relation between the deterministic part and the statistical subsystem is established by the reciprocity principle between the direct and reverberant field. The cross-spectral matrix of the reverberant forces from the $k^{\text {th }}$ subsystem follows

$$
\mathbf{S}_{f f, \text { rev }}^{(k)} \equiv \mathrm{E}\left[\mathbf{f}_{\text {rev }}^{(k)} \mathbf{f}_{\text {rev }}^{(k)}\right]=\left(\frac{4 E_{k}}{\omega \pi n_{k}}\right) \operatorname{Im}\left\{\mathbf{D}_{\mathrm{dir}}^{(k)}\right\}
$$

Here $\mathrm{E}[]$ indicates an ensemble average, $E_{k}$ is the vibrational energy of the $k^{\text {th }}$ subsystem and $n_{k}$ is its modal density. Equation (23) relates the forces acting on the FE components to the energies of the SEA subsystems.

The coupling between the deterministic and statistical components is given by Eq. (23), leading to the following result for the response of the deterministic system. The cross-spectral matrix for the responses of the FE part is expressed as 


$$
\mathbf{S}_{u u}=\mathbf{D}_{\mathrm{tot}}^{-1}\left(\mathbf{S}_{f f, \mathrm{ext}}+\sum_{k=1}^{N_{2}} \mathbf{S}_{f f, \mathrm{rev}}^{(k)}\right) \mathbf{D}_{\mathrm{tot}}^{-1^{*} \mathrm{~T}}=\mathbf{D}_{\mathrm{tot}}^{-1}\left[\mathbf{S}_{f f, \text { ext }}+\sum_{k=1}^{N_{2}}\left(\frac{4 E_{k}}{\omega \pi n_{k}}\right) \operatorname{Im}\left\{\mathbf{D}_{\mathrm{dir}}^{(k)}\right\}\right] \mathbf{D}_{\mathrm{tot}}^{-1^{*} \mathrm{~T}}
$$

where $\mathbf{S}_{f f \text { ext }}$ is the cross-spectrum of the forces applied to the deterministic system.

The terms on the right-hand side of Eq. (21) can be computed from the physical properties of the system, apart from the subsystem energy $E_{j}$, for which a power balance condition is required for each subsystem. This leads to the following power balance equations of the $j^{\text {th }}$ subsystem

$$
\omega\left(\eta_{j}+\eta_{\mathrm{d}, j}\right) E_{j}+\sum_{\substack{k=1 \\ k \neq j}}^{N_{j}}\left(\omega \eta_{j k} E_{j}-\omega \eta_{k j} E_{k}\right)=P_{\mathrm{in}, j}+P_{\mathrm{in}, j}^{\mathrm{ext}}
$$

where the term $\eta_{\mathrm{d}, j}$ represents an additional subsystem loss factor owing to the energy dissipation in the master system, and $N_{j}$ is the number of SEA subsystems coupled with the $j^{\text {th }}$ subsystem. Moreover

$$
\begin{gathered}
\omega \eta_{\mathrm{d}, j}=\left(\frac{2}{\pi n_{j}}\right) \sum_{r, s} \operatorname{Im}\left\{D_{\mathrm{d}, r s}\right\}\left(\mathbf{D}_{\mathrm{tot}}^{-1} \operatorname{Im}\left\{\mathbf{D}_{\mathrm{dir}}^{(j)}\right\} \mathbf{D}_{\mathrm{tot}}^{-*^{* \mathrm{~T}}}\right)_{r s} \\
\omega \eta_{j k}=\left(\frac{2}{\pi n_{j}}\right) \sum_{r, s} \operatorname{Im}\left\{D_{\mathrm{dir}, r s}^{(j)}\right\}\left(\mathbf{D}_{\mathrm{tot}}^{-1} \operatorname{Im}\left\{\mathbf{D}_{\mathrm{dir}}^{(k)}\right\} \mathbf{D}_{\mathrm{tot}}^{- \text {- }^{*} \mathrm{~T}}\right)_{r s}
\end{gathered}
$$

The power input to the $j^{\text {th }}$ subsystem from forces applied on the deterministic part

$$
P_{\mathrm{in}, j}^{\mathrm{ext}}=\left(\frac{\omega}{2}\right) \sum_{r, s} \operatorname{Im}\left\{D_{\mathrm{dir}, r s}^{(j)}\right\}\left(\mathbf{D}_{\mathrm{tot}}^{-1} \mathbf{S}_{f f, \mathrm{ext}} \mathbf{D}_{\mathrm{tot}}^{-1^{*} \mathrm{~T}}\right)_{r s}
$$

where $r s$ denotes the $r^{\text {th }}$ row and $s^{\text {th }}$ column element in a matrix. The complete response of the SEA subsystem allowing for coupling with the FE components is obtained by solving Eq. (25) to yield the vibrational energy. Equation (24) is used to obtain the response of the deterministic system. Then, from the vibration, the sound pressure at any point in space due to the bridge can be determined.

\subsection{Acoustic radiation}

In order to calculate the noise emission, each FE component or SEA subsystem of a composite 
bridge can be considered as a rectangular plate. The radiated sound power of plate $j$ with mean-square velocity $\left\langle v_{j}^{2}\right\rangle$ can be expressed as [39]

$$
W_{j}=\rho_{0} c_{0} \sigma_{j} S_{j}\left\langle v_{j}^{2}\right\rangle
$$

where $\rho_{0}$ and $c_{0}$ denote the air density and the sound speed in air respectively, $\sigma_{j}$ is the radiation ratio or radiation efficiency which can be derived from the analytical solutions in [1] and $S_{j}$ is the area of plate $j$. The mean-square velocity $\left\langle v_{j}^{2}\right\rangle$ is derived from the energy $E_{j}$ of the SEA subsystems or the spatially averaged nodal responses of the FE components.

The mean-square sound pressure radiated by the bridge is written as [19]

$$
\left\langle p^{2}\right\rangle=\sum_{j} \frac{\rho_{0} c_{0} W_{j}}{A_{j}} G_{j}
$$

where $A_{j}$ is the area over which the sound power from plate $j$ is distributed. Expressions for this can be found in [19] in which each plate is represented by plane, line or point sources depending on the distance from the receiver; $G_{j}$ is the ground reflection term which can be derived from [1].

\section{Case study}

\subsection{Outline of the composite bridge}

The method is applied to a composite railway bridge with ballasted track. Field tests have been carried out to measure the vibration and noise from this bridge which are used to verify the proposed method. The continuous steel-concrete composite bridge is on a straight line with a span layout of $(32+40+32) \mathrm{m}$, as shown in Fig. 2(a). The dual-track bridge has a $12.4 \mathrm{~m}$ wide deck with a track spacing of $4.6 \mathrm{~m}$. The bridge consists of two I-section steel girders $6 \mathrm{~m}$ apart, and a pre-stressed concrete deck which is cast on the steel girders, as shown in Fig. 2(b). The steel girder has a flange of width $1.2 \mathrm{~m}$ and a web of height $2.5 \mathrm{~m}$. The thicknesses of the web and flange are 24 $\mathrm{mm}$ and $50 \mathrm{~mm}$, respectively. Lateral bracing is included between the two steel girders at intervals 
of $4 \mathrm{~m}$. The thickness of the cast-in-situ bridge deck ranges from 0.2 to $0.487 \mathrm{~m}$. The upper flanges of the girders are connected to the deck via shear studs. The bridge is supported on double-column piers.

(a)

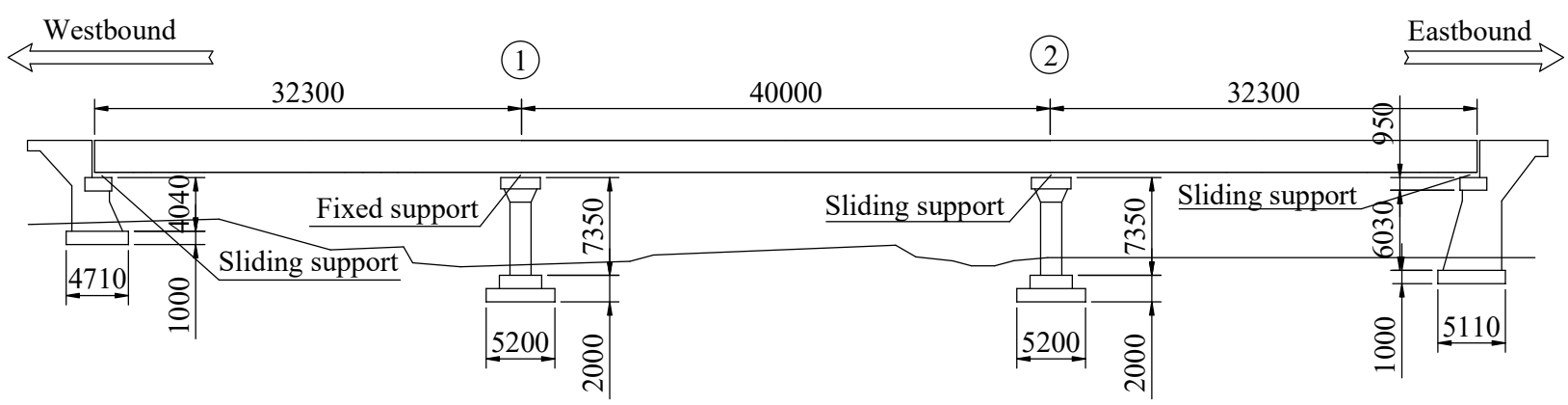

(b)

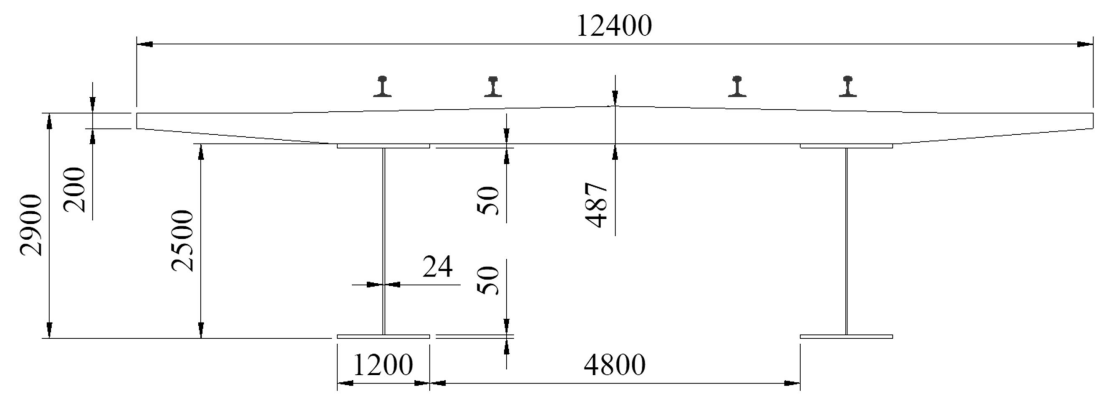

Fig. 2. Sketch of the bridge: (a) Elevation view; (b) Cross-section (unit: $\mathrm{mm}$ ).

\subsection{Roughness}

The track is fitted with continuously welded rail, so impact loads caused by rail joints can be neglected. The rail roughness on the bridge could not be measured since this high speed line is in operation and access to the track on the deck was not available. Because the measurement of wheel roughness of high-speed trains is also not available, the wheel roughness is ignored in the case study. Nevertheless, the wheel roughness of disc-braked rolling stock is usually low compared with the rail roughness [40]. Wei [41] found that the roughness of several typical Chinese railway lines is close to the limit curve given in the previous standard, ISO 3095:2005 [42]. So the RMS roughness $\Delta$ in 1/3 octave bands described in ISO 3095:2005 is adopted: 


$$
20 \lg \left(\frac{\Delta}{\Delta_{0}}\right)=\left\{\begin{array}{lr}
18.435 \lg \lambda+27.194 & 0.01 \leq \lambda \leq 0.63 \\
-9.7 & 0.00315 \leq \lambda<0.01
\end{array}\right.
$$

where $\Delta_{0}=1 \mu \mathrm{m}$ is the reference roughness, $\lambda=v / f$ is the wavelength, with $v$ the speed in $\mathrm{m} / \mathrm{s}$ and $f$ the frequency.

The excitation of the wheel-rail system will be weakened if the wavelength of the roughness is shorter than the length of the contact patch in the rolling direction, denoted by $2 a$. This effect is called contact filtering that can be approximated by the following filtering transfer function [1]

$$
\left|H\left(k_{0}\right)\right|^{2}=\left[1+\frac{\pi}{4}\left(k_{0} a\right)^{3}\right]^{-1}
$$

where $k_{0}$ means the wavenumber of the roughness, $k_{0}=2 \pi / \lambda$. In the current study the vehicle speed is $200 \mathrm{~km} / \mathrm{h}(55.6 \mathrm{~m} / \mathrm{s})$, so for the chosen frequency range 17.8 to $1780 \mathrm{~Hz}$, the wavelength range of the roughness extends from 0.0312 to $3.12 \mathrm{~m}$. The $1 / 3$ octave band roughness spectra with and without the contact filter are shown in Fig. 3.

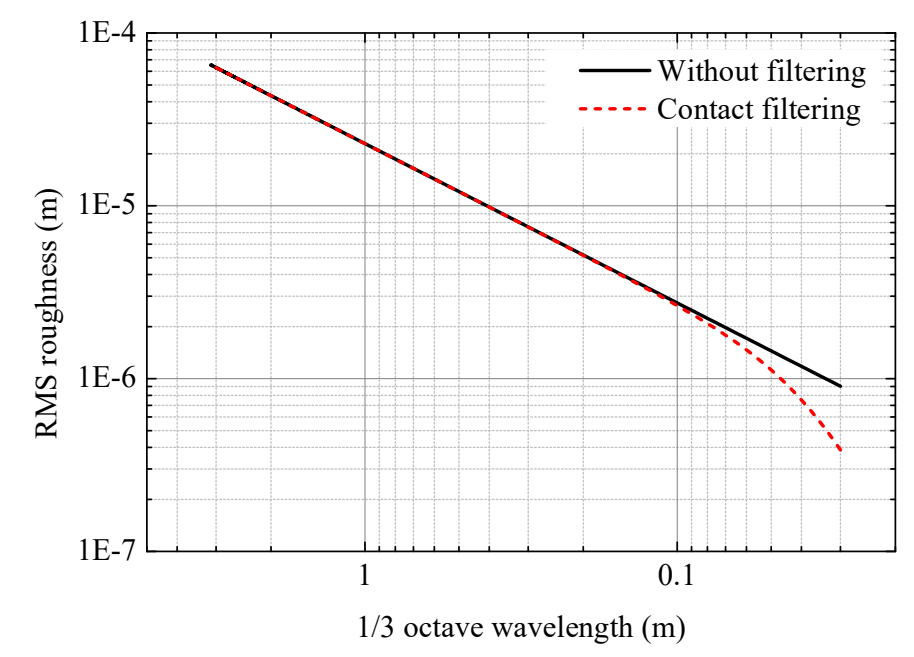

Fig. 3. Assumed 1/3 octave band roughness spectra from ISO 3095:2005.

The wheel-rail forces and forces transmitted to the bridge per unit roughness can be obtained by using Eqs. (1) and (17) in narrow bands; the frequency resolution is $1 \mathrm{~Hz}$ in this study. Then these force results will be averaged into $1 / 3$ octave bands. Multiplying these forces by the filtered 
roughness spectrum from Eq. (31) in 1/3 octave bands results in the final wheel-rail forces and forces transmitted to the bridge.

\subsection{Forces transmitted to bridge}

For high-speed trains in China, with a formation of eight or sixteen vehicles, the vehicles on the bridge at any given time may be all powered vehicles, or a mixture of powered and trailer vehicles. Here, for simplicity the situation with all powered vehicles on the bridge is used in the predictions. The parameters of the motor vehicle used in the calculation of the wheel receptance are listed in Table 1 [19].

Table 1 Parameters of motor vehicle.

\begin{tabular}{lccc}
\hline \multicolumn{1}{c}{ Parameter } & Symbol & Units & Value \\
\hline Quarter of bogie mass & $m_{\mathrm{b}}$ & $\mathrm{kg}$ & 800 \\
Half of wheel-set mass & $m_{\mathrm{w}}$ & $\mathrm{kg}$ & 1000 \\
Vertical stiffness of primary suspension & $k_{1}$ & $\mathrm{~N} / \mathrm{m}$ & $1.176 \times 10^{6}$ \\
Vertical damping of primary suspension & $c_{1}$ & $\mathrm{~N} \cdot \mathrm{s} / \mathrm{m}$ & $2.5 \times 10^{4}$ \\
Half of bogie spacing & $l_{\mathrm{b}}$ & $\mathrm{m}$ & 8.75 \\
Half of wheelbase & $l_{\mathrm{w}}$ & $\mathrm{m}$ & 1.25 \\
Vehicle length & $l_{\mathrm{c}}$ & $\mathrm{m}$ & 26 \\
Modal stiffness & $k_{\mathrm{m}}$ & $\mathrm{N} / \mathrm{m}$ & $4.4 \times 10^{9}$ \\
Loss factor of modal spring & $\eta_{\mathrm{m}}$ & $\mathrm{N}$ & 0.2 \\
Stiffness of wheel-rail contact spring & $k_{\mathrm{H}}$ & $\mathrm{N} / \mathrm{m}$ & $1.325 \times 10^{9}$ \\
\hline
\end{tabular}

The track on the bridge is ballasted track with CN 60 rail and a standard gauge of $1435 \mathrm{~mm}$; there are 191 sleepers included in the track model; the corresponding parameters are listed in Table 2 [43]. 
After the receptances of rail and monobloc sleeper are obtained, the receptance matrix of the track could be produced using Eq. (11). The computed receptances of the track are shown in Fig. 4(a). Both a point receptance and a transfer receptance to the response at $2.5 \mathrm{~m}$ (equal to the wheelbase) away from the excitation point are shown. The transfer receptance is far lower than the driving point receptance, particularly in the frequency range below $300 \mathrm{~Hz}$. A peak occurs in the driving point receptance at $249 \mathrm{~Hz}$, coinciding with the natural frequency of the rail mass on the stiffness of the fastener system including the sleeper flexibility and the ballast resilience. The excitation point is close to the mid-span between two sleepers. At this point, a peak occurs in the driving point receptance at $1266 \mathrm{~Hz}$, corresponding to the pinned-pinned mode of the discretely supported rail. The decay rate is obtained using the formula in [44] and plotted in Fig. 4(b). The decay rate below $200 \mathrm{~Hz}$ is around $10 \mathrm{~dB} / \mathrm{m}$ and it drops to less than $1 \mathrm{~dB} / \mathrm{m}$ above about $500 \mathrm{~Hz}$ as waves propagate freely along the track.

Table 2 Track parameters.

\begin{tabular}{lccc}
\hline \multicolumn{1}{c}{ Parameter } & Symbol & Units & Value \\
\hline Rail density & $\rho_{\mathrm{r}}$ & $\mathrm{kg} / \mathrm{m}^{3}$ & 7860 \\
Rail cross-sectional area & $A_{\mathrm{r}}$ & $\mathrm{m}^{2}$ & $7.745 \times 10^{-3}$ \\
Rail Young's modulus & $E_{\mathrm{r}}$ & $\mathrm{Pa}$ & $2.059 \times 10^{11}$ \\
Rail shear modulus & $G_{\mathrm{r}}$ & $\mathrm{Pa}$ & $7.7 \times 10^{10}$ \\
Second moment of area of rail & $I_{\mathrm{r}}$ & $\mathrm{m}^{4}$ & $3.217 \times 10^{-5}$ \\
Rail loss factor & & & 0.01 \\
Rail shear coefficient & $\eta_{\mathrm{r}}$ & $/$ & 0.45 \\
Fastener vertical stiffness & $\kappa$ & $\mathrm{N} / \mathrm{m}$ & $1.2 \times 10^{8}$ \\
\hline
\end{tabular}


Fastener loss factor

Fastener spacing

Sleeper Young's modulus

Sleeper shear modulus

Sleeper density

Sleeper length

Sleeper average cross-sectional area

Second moment of area of sleeper

Sleeper loss factor

Sleeper shear coefficient

Ballast vertical stiffness per unit length along the sleeper

Ballast vertical damping per unit length along the sleeper $\eta_{\mathrm{f}}$

$d_{\mathrm{f}}$

$\mathrm{m}$

0.545

$E_{\mathrm{s}}$

$\mathrm{Pa}$

$5.7 \times 10^{10}$

$G_{\mathrm{S}}$

$\mathrm{Pa}$

$2.38 \times 10^{10}$

$\rho_{\mathrm{s}}$

$\mathrm{kg} / \mathrm{m}^{3}$

2648

$\mathrm{m}$

$A_{\text {s }}$

$\mathrm{m}^{2}$

$I_{\mathrm{s}}$

$\mathrm{m}^{4}$

$1.27 \times 10^{-4}$

$\eta_{\mathrm{s}}$

/

0.015

$\kappa_{\mathrm{s}}$

/

0.83

$k_{\mathrm{b}}$

$\mathrm{N} / \mathrm{m}^{2}$

$6.8 \times 10^{7}$

$c_{\mathrm{b}}$

$\mathrm{N} \cdot \mathrm{s} / \mathrm{m}^{2}$

$2.352 \times 10^{4}$ (a)

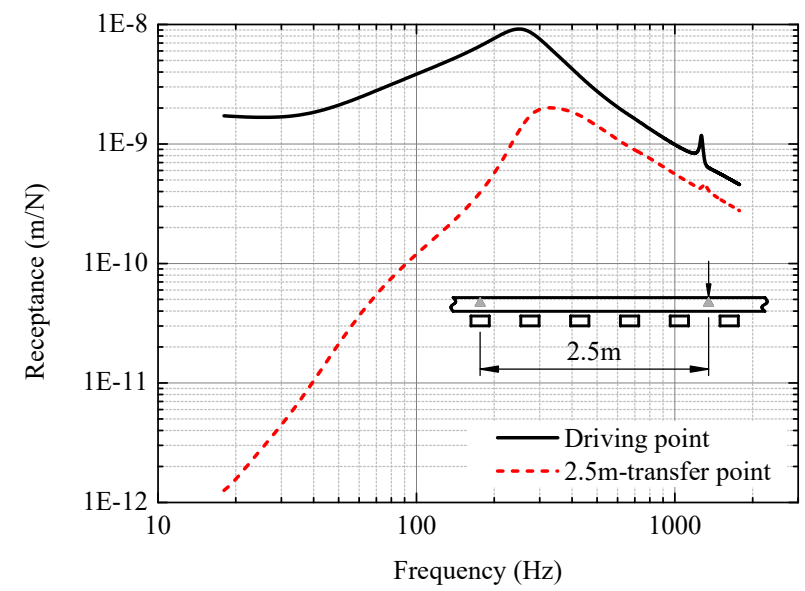

(b)

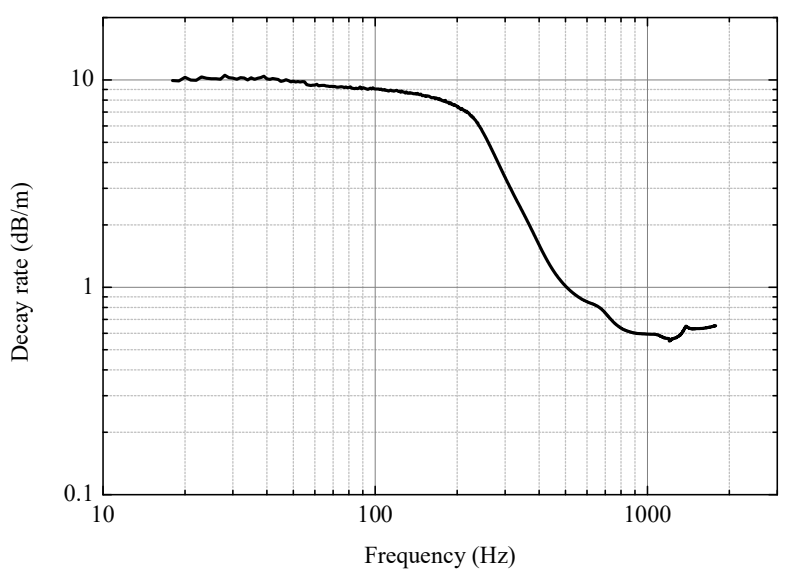

Fig. 4. Track dynamic properties: (a) Receptances; (b) Decay rate.

A total of 17 wheels, distributed along the rail on the bridge, were considered in the wheel-rail interaction computation. The computed wheel-rail force above the sleeper at the centre of the bridge 
is shown in Fig. 5. Results are shown for a single wheel-rail contact without the transfer receptances of the rail and for multiple contacts allowing for the coupling between all the wheel-rail contacts by the transfer receptances. Fig. 5(a) shows the narrow-band force for a unit roughness and Fig. 5(b) shows the 1/3 octave band spectrum for the ISO 3095:2005 roughness. There is a peak in the wheel-rail force at $85 \mathrm{~Hz}$, this being the natural frequency of the wheel-rail system at which the wheel mass bounces on the track stiffness. The wheel-rail force computed with the inclusion of the transfer receptances is smooth in the frequency region below $200 \mathrm{~Hz}$; however, it has large fluctuations at higher frequencies. These results demonstrate that the wheel-rail forces with and without consideration of the transfer receptances of the track are quite similar below $315 \mathrm{~Hz}$ where the decay rate is high, but the wheel-rail force without the transfer receptances of the track is an under-estimate at higher frequencies.

(a)

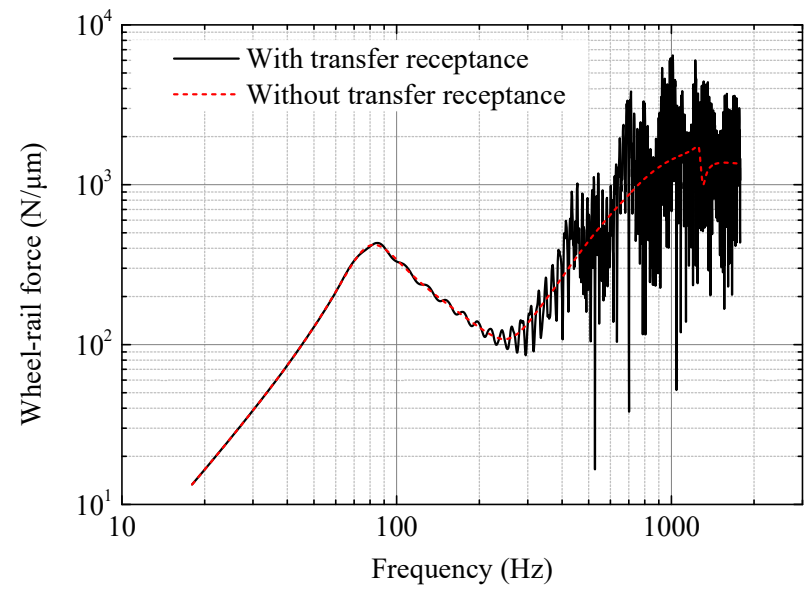

(b)

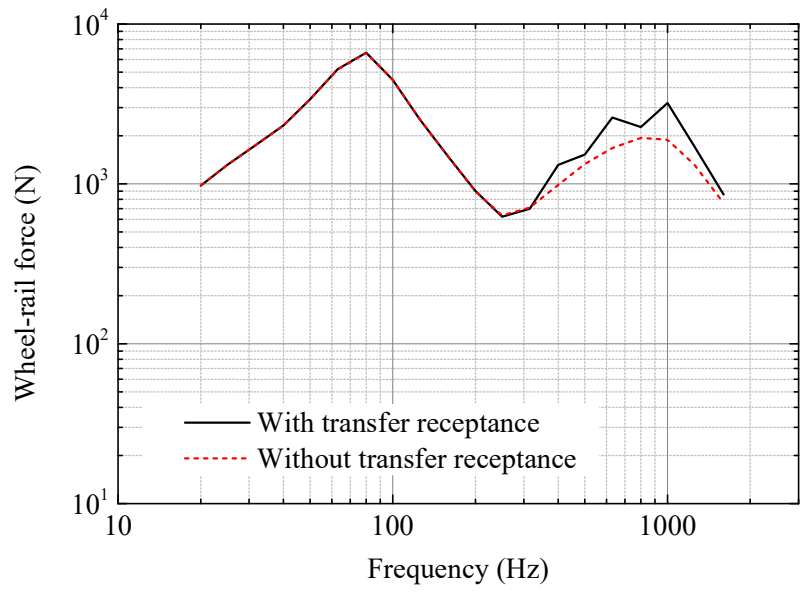

Fig. 5. Computed wheel-rail forces excited by: (a) roughness of $1 \mu \mathrm{m}$ at each frequency; (b) roughness from ISO 3095:2005.

Substituting the computed wheel-rail forces into Eq. (11), the sleeper displacement is obtained. Subsequently, the forces transmitted to the bridge can be derived from the sleeper displacement according to Eq. (17). The forces at three example positions $(0 \mathrm{~m}, 0.545 \mathrm{~m}$, and $1.09 \mathrm{~m}$ from the 
wheel above a sleeper at the centre of the bridge) are shown in Fig. 6. The force below the wheel again has a peak around $80 \mathrm{~Hz}$. As the distance from the wheel increases, the force generally becomes lower owing to the high decay rate of track below $200 \mathrm{~Hz}$. The force at $1.09 \mathrm{~m}$ from the wheel includes multiple peaks below $200 \mathrm{~Hz}$, due to interference between the wheel-rail forces from the two adjacent wheels. Above $500 \mathrm{~Hz}$ the forces at these three sleepers have similar magnitudes and exhibit considerable fluctuation as seen in the wheel-rail force. The cross spectra of all forces transmitted to the bridge are converted into 1/3 octave bands and then substituted into Eqs. (24) and (28) to resolve the hybrid FE-SEA model of the bridge.

(a)

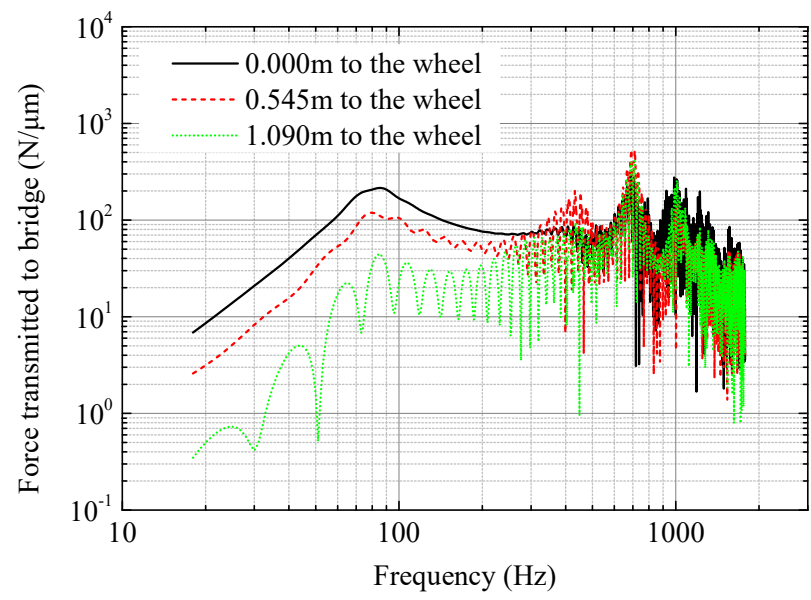

(b)

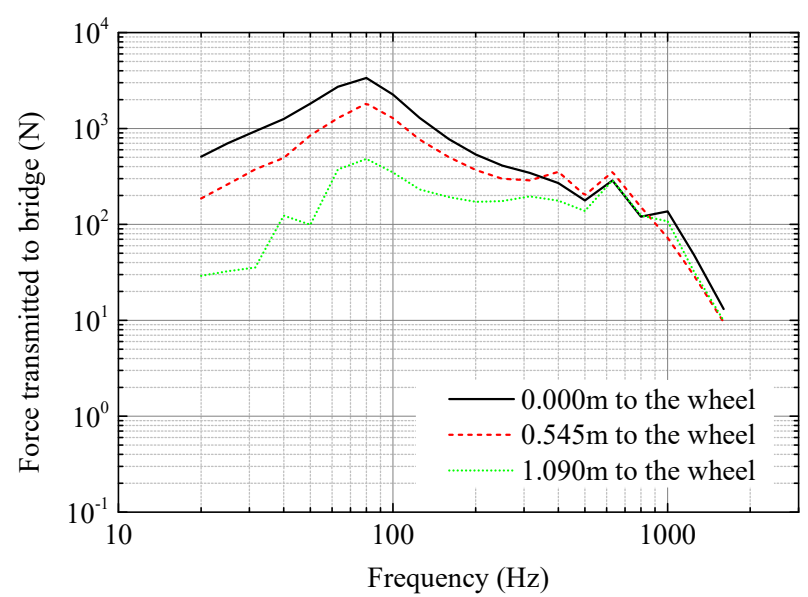

Fig. 6. Computed forces transmitted to the bridge: (a) the roughness of $1 \mu \mathrm{m}$; (b) the roughness of ISO 3095.

\subsection{Bridge model}

The material properties of the composite bridge were provided by the railway operator and are listed in Table 3. In the hybrid FE-SEA model of the composite bridge, FE is used for the concrete deck, and the SEA method is used to model the steel girder, as shown in Fig. 7. The FE mesh size should be smaller than $1 / 6$ of the modal wavelength of the deck under free-free conditions at upper frequency. This would require an element size of $0.18 \mathrm{~m}$ for the concrete deck, given the modal wavelength of $1.08 \mathrm{~m}$ around $1780 \mathrm{~Hz}$. Eventually, the element size of the deck is rounded up to 0.2 
$\mathrm{m}$ because the dominant frequency of the bridge-borne noise is much lower than the upper frequency. The web and flange are modelled by different SEA subsystems and are divided at the section of the bridge bearings. The number of modes and modal overlap factor of the web and flange in each frequency band are shown in Fig. 8, which meet the requirement of SEA in most frequency bands. The coupling loss factors between the web and flange, as shown in Fig. 9, in combination with the modal density in Fig. 8, illustrate the reciprocity relationship between the two subsystems. In the hybrid FE-SEA model, the bridge is composed of 32440 shell finite elements and 18 SEA subsystems.

Table 3 Material properties of the composite bridge.

\begin{tabular}{cccc}
\hline Parameter & Symbol & Units & Value \\
\hline Steel density & $\rho_{\text {st }}$ & $\mathrm{kg} / \mathrm{m}^{3}$ & 7850 \\
Steel Young's modulus & $E_{\mathrm{st}}$ & $\mathrm{GPa}$ & 206 \\
Steel loss factor & $\eta_{\mathrm{st}}$ & $/$ & 0.015 \\
Concrete density & $\rho_{\mathrm{c}}$ & $\mathrm{kg} / \mathrm{m}^{3}$ & 2650 \\
Concrete Young's modulus & $E_{\mathrm{c}}$ & $\mathrm{GPa}$ & 35 \\
Concrete loss factor & $\eta_{\mathrm{c}}$ & $/$ & 0.03 \\
\hline
\end{tabular}

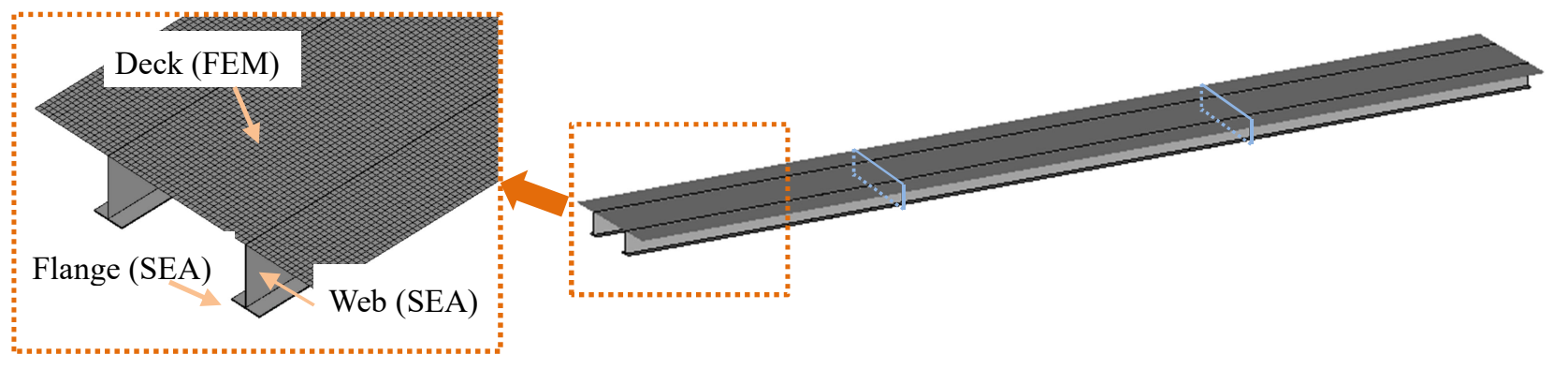

Fig. 7. Hybrid FE-SEA model of the bridge. 
(a)

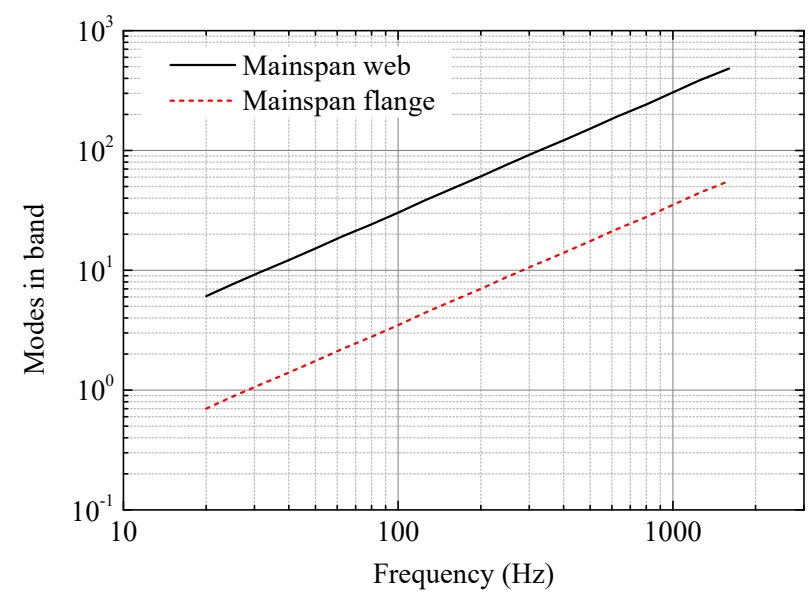

(b)

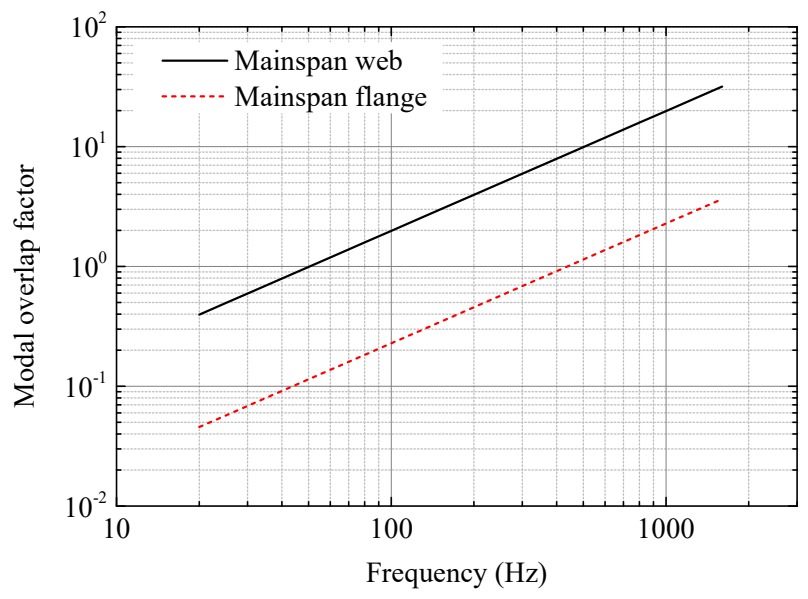

Fig. 8. Asymptotic estimates of the modal parameters in each $1 / 3$ octave band of main span web and flange: (a)

Number of modes; (b) Modal overlap factor.

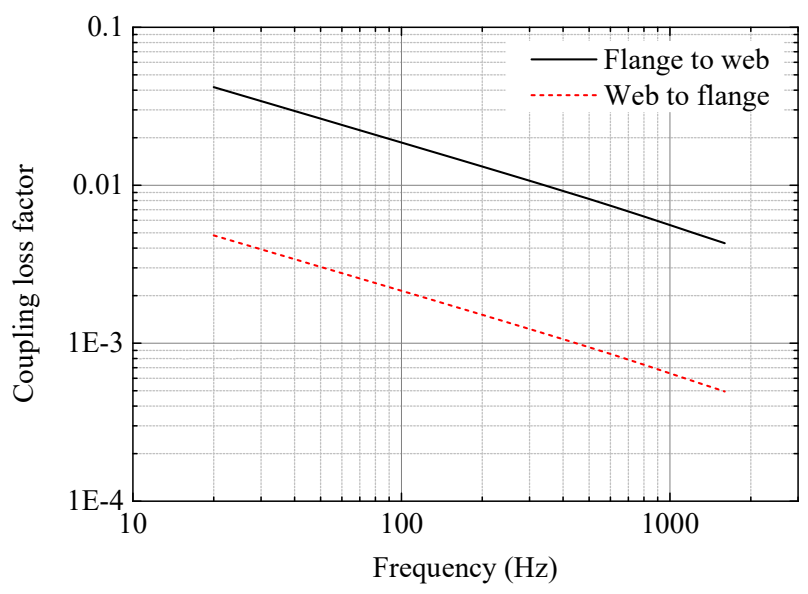

Fig. 9. Coupling loss factors between the web and flange.

\subsection{Experimental set-up}

Noise and vibration measurements have been conducted on the bridge described in Section 3.1. The noise was measured at two positions: $\mathrm{S} 1$ is directly beneath the bridge centreline, and S2 is 7.5 $\mathrm{m}$ to one side of the centre of the west-bound track, i.e. $9.8 \mathrm{~m}$ from the centreline (see Fig. 10). Both microphones were located $1.5 \mathrm{~m}$ above the ground which was flat with a bituminous pavement. Accelerometer V1 was mounted below the centre of the deck; V2 and V3 measured the normal accelerations of the web and lower flange, respectively. The effective frequency range of the piezoelectric accelerometers is from $0.5 \mathrm{~Hz}$ to $10 \mathrm{kHz}$, with a maximum response of $50 \mathrm{~g}$. The 
frequency range of the microphones is from $3 \mathrm{~Hz}$ to $20 \mathrm{kHz}$, and the response range is a sound pressure level from 16 to $146 \mathrm{~dB}$. The sampling frequency was $10.24 \mathrm{kHz}$. The results were analysed over the same frequency range as used in the model, i.e. 1/3 octave bands between $20 \mathrm{~Hz}$ and 1.6 kHz. Figure 11(a) shows the experimental site and Fig. 11(b) the microphone at S2. The train speed was obtained from the train's length and passing time. It was sunny and the wind speed was less than $2-3 \mathrm{~m} / \mathrm{s}$.

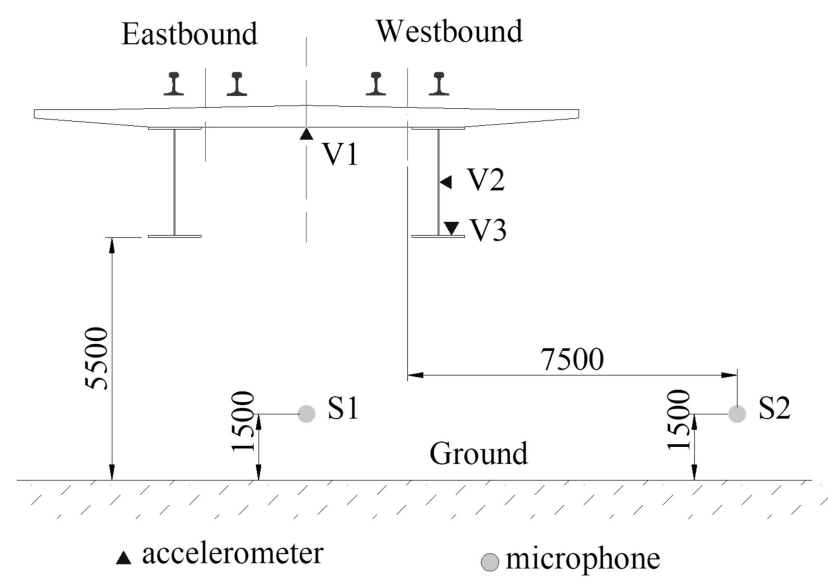

Fig. 10. Layout of acceleration and noise measuring points (unit: $\mathrm{mm}$ ).

(a)

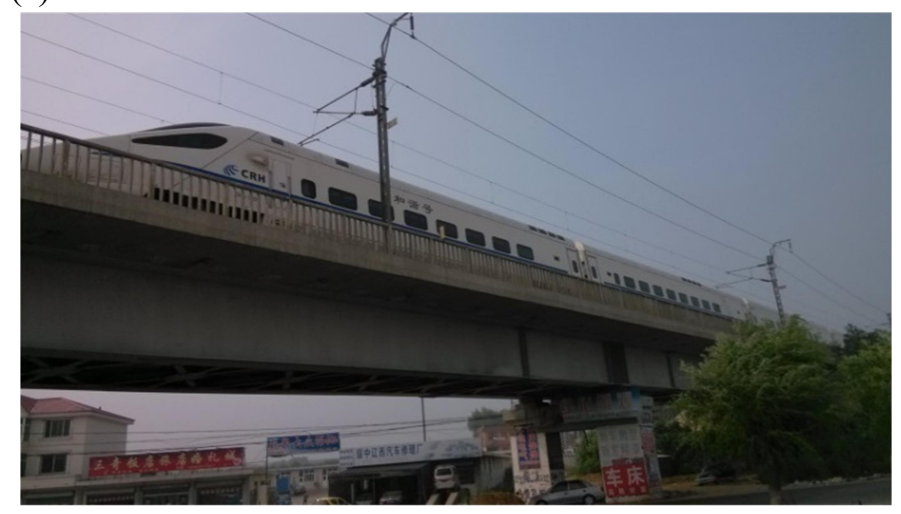

(b)

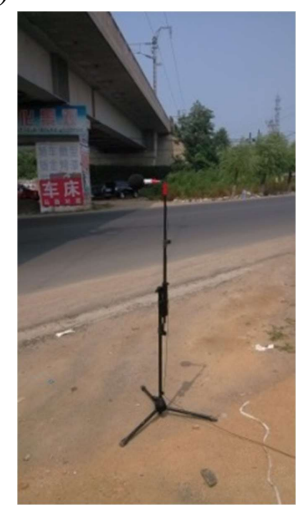

Fig. 11. Images of the vibration and noise measurement: (a) Image of the bridge; (b) Microphone of S2.

\subsection{Comparison between the measured and computed responses}

The measured and computed vibrational acceleration levels are shown in Fig. 12. The deck acceleration in the frequency region $40-100 \mathrm{~Hz}$ is larger than in other frequency regions. The accelerations of the web and lower flange are 5-10 dB greater than that of the deck for frequencies 
above $50 \mathrm{~Hz}$. They have peaks in the acceleration spectrum at $63 \mathrm{~Hz}$ and $80 \mathrm{~Hz}$, respectively, close to the peak in the wheel-rail force. From Fig. 12 it can be seen that the simulated acceleration spectra coincide with the measured ones. Especially the fact that the relative levels at the three locations are correctly estimated, provides verification of the proposed method for vibration prediction.

(a)

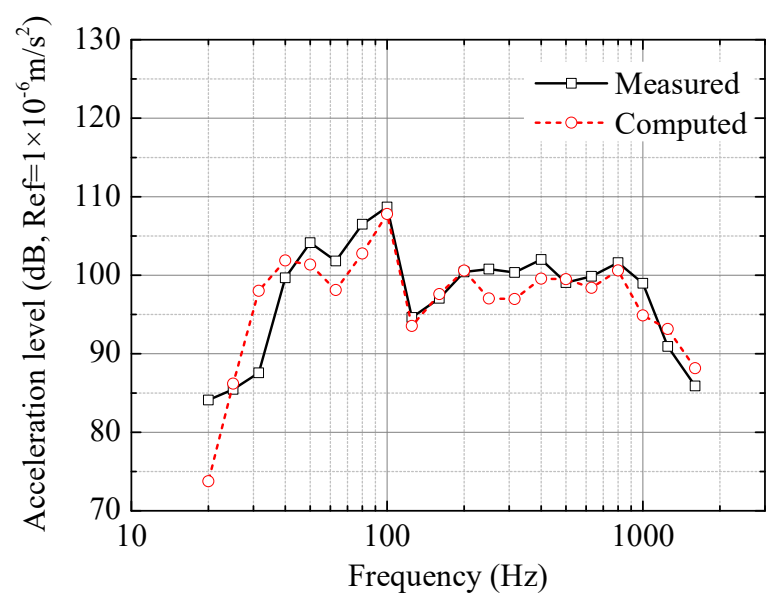

(b)

(c)
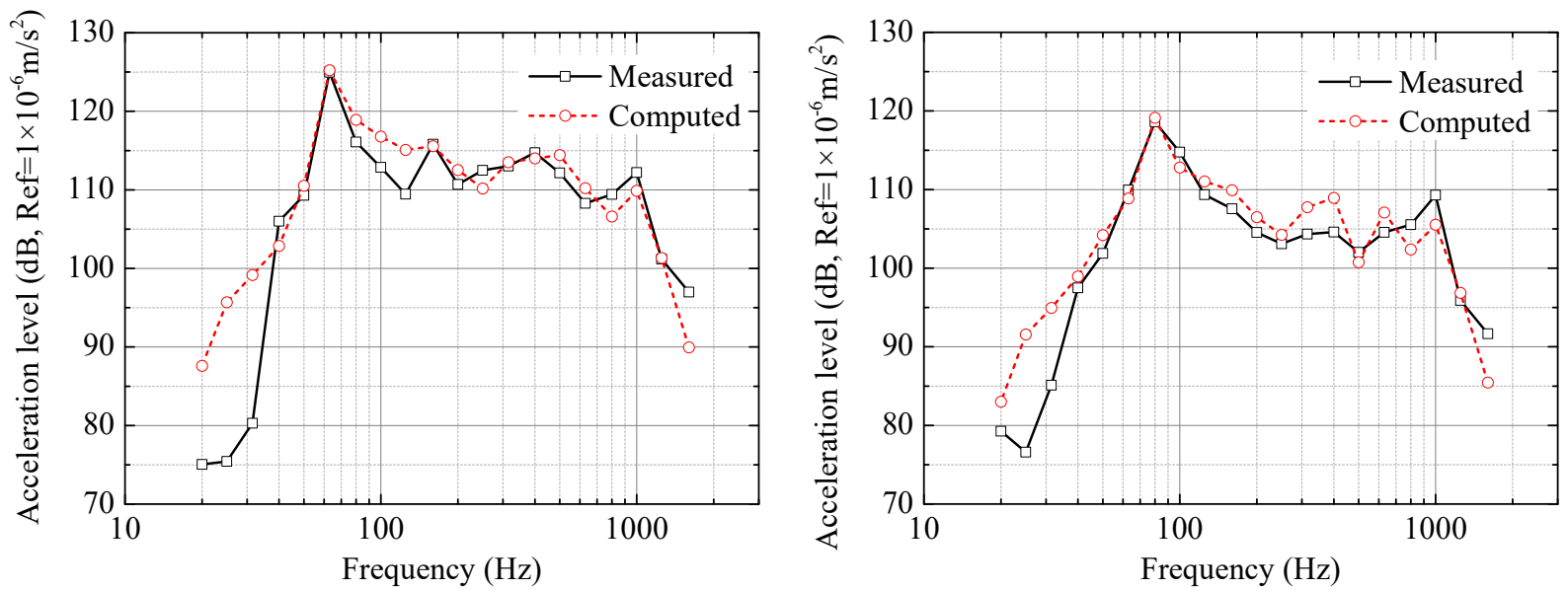

Fig. 12. Comparison between the measured and computed vibrational accelerations: (a) V1; (b) V2; (c) V3.

The predicted and measured sound pressure levels (SPLs) at both receiver points are shown in Fig. 13. The spectrum of the A-weighted SPL is fairly flat between 80 and $1000 \mathrm{~Hz}$ owing to the larger force transmitted to the bridge at low frequencies, the effect of the A-weighting and the higher radiation efficiency at high frequencies. The radiation efficiencies of the different 
components, which are derived from the formulae in [1], are shown in Fig. 14. The computed SPL at S1 (see Fig. 13 (a)), radiated solely by the bridge, agrees with the measured one in the main frequency range since the rolling noise and aerodynamic noise are shielded to a large extent by the deck. The predicted noise at S2 (see Fig. 13 (b)) agrees well with the measured one in the region between 40 and $800 \mathrm{~Hz}$, whereas for higher frequencies the prediction model underestimates the noise, which will be influenced by the rolling noise which is not included in the model. Generally, the agreement between the measured and predicted results verifies the proposed prediction approach for structure-borne noise of composite bridges.

(a)

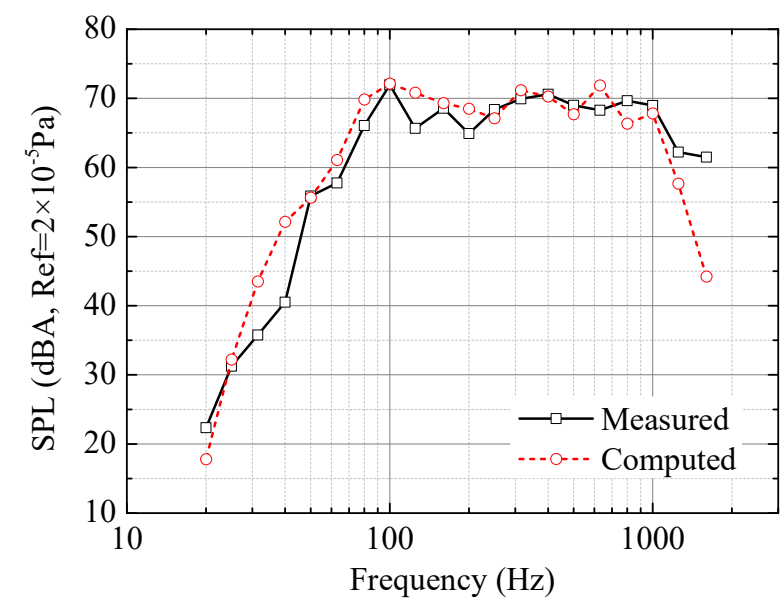

(b)

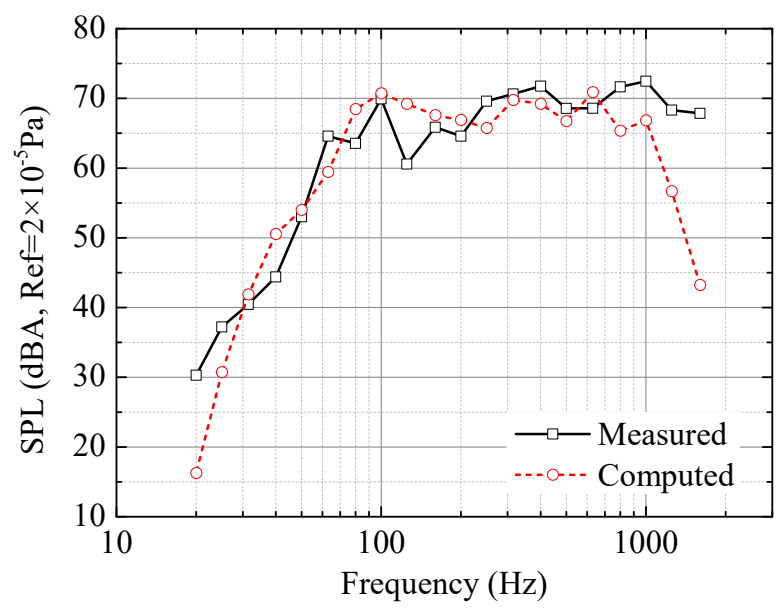

Fig. 13. Comparison between the measured and computed A-weighted SPLs: (a) S1; (b) S2.

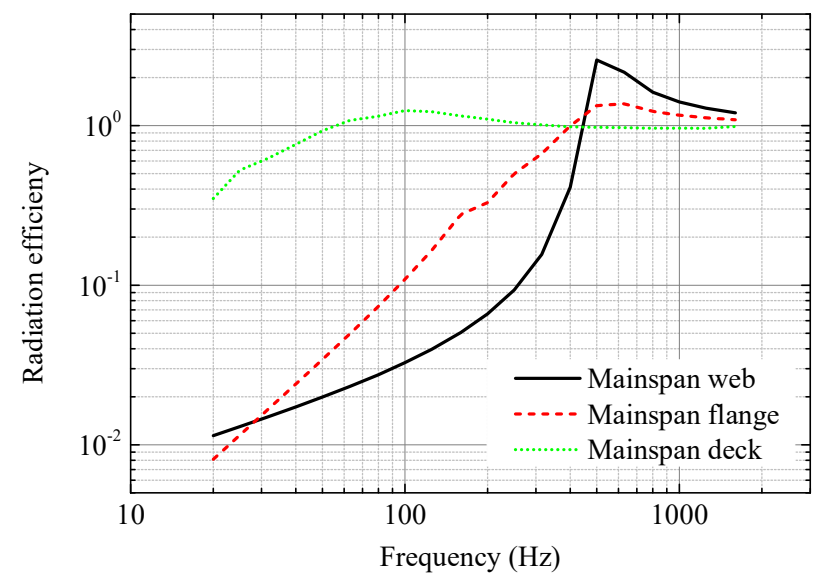

Fig. 14. Radiation efficiency of bridge components. 


\subsection{Comparison of FE, SEA and FE-SEA models}

In this Section the hybrid FE-SEA model is compared with models of the same composite bridge based purely on FEM or purely on SEA. This will allow the advantages and disadvantages of the three models to be assessed through a comparison of the accuracy and efficiency of calculating the vibration and noise of the composite railway bridge. In the SEA-only model the power input to the bridge is derived from the bridge mobility from the FE model and the forces transmitted to the bridge. It has 30 subsystems whereas the FE-only model has 225420 shell elements. The calculation times for the vibration and noise from the composite bridge using the three models are listed in Table 4 for a $3.2 \mathrm{GHz}$ CPU with 16 GB of RAM. Obviously, the purely SEA model has a very high calculation efficiency. The calculation time of the purely FE model is about 11 times that of the hybrid FE-SEA model when the frequency range extends up to $1780 \mathrm{~Hz}$, and the advantage of the hybrid FE-SEA model will be more obvious as the analysis frequency is increased.

Table 4 Comparison of calculation efficiency.

\begin{tabular}{cccc}
\hline Models & Number of elements & Number of subsystems & Calculation time \\
\hline SEA model & $/$ & 30 & $0.6 \mathrm{~s}$ \\
FE-SEA model & 32440 & 18 & $111 \mathrm{~min}$ \\
FE model & 225420 & $/$ & $20.5 \mathrm{~h}$ \\
\hline
\end{tabular}

The computed vibration and noise of the composite bridge are illustrated in Fig. 15. At high frequencies, the results derived from the SEA and hybrid FE-SEA models are similar and close to the measured values. In the mid-frequency region, the FE-SEA calculation is closest to the measured data. At low frequencies, the responses from the FE model have the best approximation to the measurement. The hybrid FE-SEA model provides a good balance between accuracy and efficiency for computing the vibration and noise of this composite bridge. 
(a)

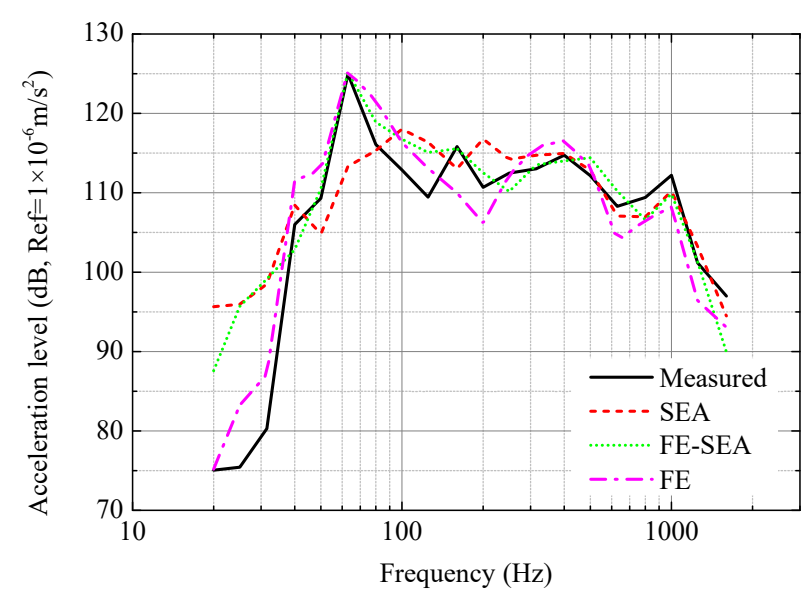

(b)

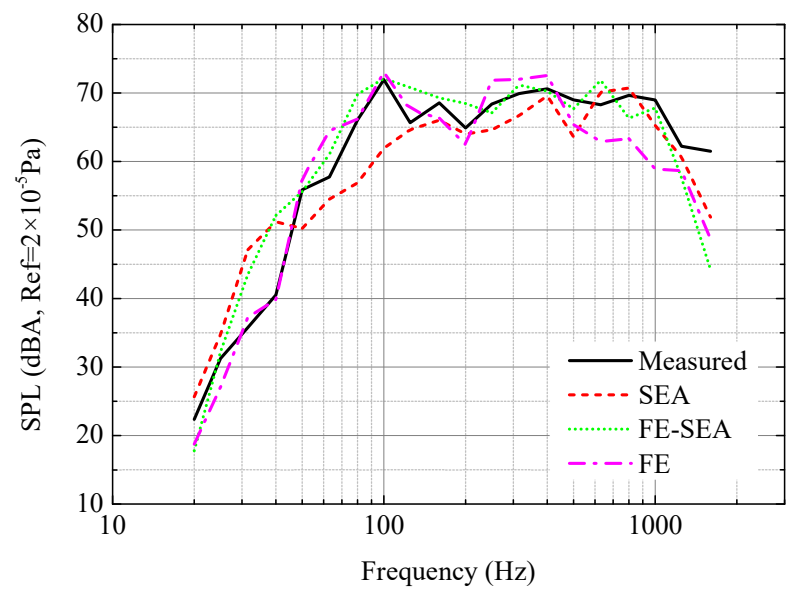

Fig. 15. Comparison of accuracy: (a) Accelerations at V2; (b) SPL at S1.

\section{Discussion}

\subsection{Sound contributions}

The bridge was divided into three parts: girder webs, lower flanges, and bridge deck, to investigate the noise contributions from the main components. The spectra of the noise at S1 and S2 radiated from the three components are shown in Fig. 16. It is found that the deck dominates the noise emanating from the bridge below $125 \mathrm{~Hz}$, while the web radiates the most noise above $400 \mathrm{~Hz}$. In the region between 125 and $400 \mathrm{~Hz}$, all the three components have significant contributions to the overall noise from the bridge.

(a)

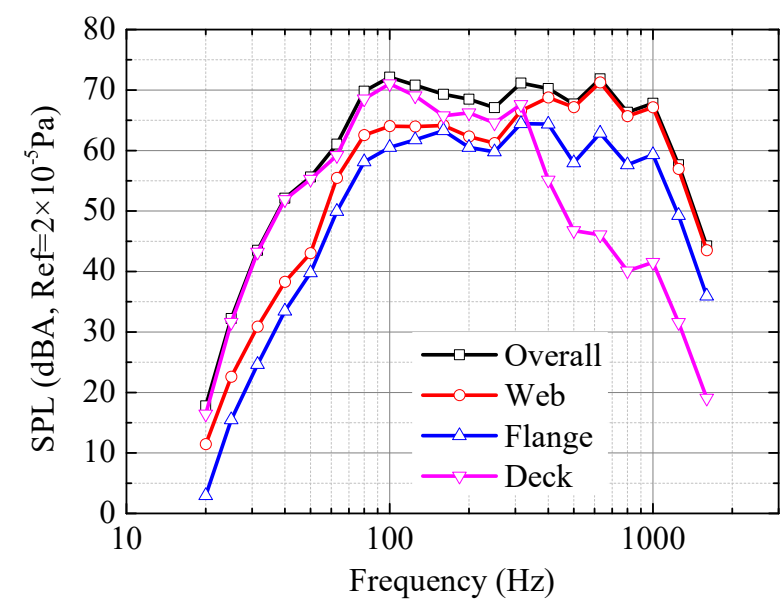

(b)

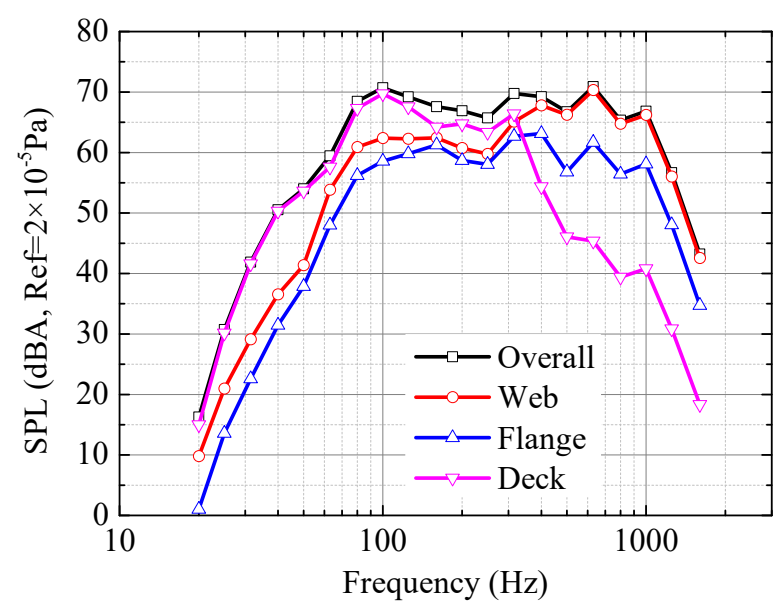

Fig. 16. Predicted A-weighted SPL spectra from the webs, flanges, and deck: (a) S1; (b) S2. 
Table 5 illustrates the overall noise level radiated by the three components at S2. The proportion of the squared pressure from the web is the highest (50.1\%), followed by bridge deck (35.1\%), and then the lower flange (14.8\%).

Table 5 Contributions of various components to SPL at S2.

\begin{tabular}{cc}
\hline Component & A-weighted SPL (dBA) \\
\hline Web & 76.1 \\
Flange & 70.8 \\
Deck & 74.6 \\
\hline Left span & 67.8 \\
Main span & 78.4 \\
Right span & 67.6 \\
\hline Total & 79.1 \\
\hline
\end{tabular}

To determine the influence of the bridge spans on the predicted noise, the SPL contribution of the left, main, and right span were computed, as listed in Table 5. The noise generated by the left and right spans together represents $14.5 \%$ of the acoustic radiation of the entire bridge. Because S1 and S2 are located in the cross section in the middle of the main span, the contribution of the main span is similar to the total SPL of the entire bridge, whereas the noise emitted from the side spans is much lower than that from the main span at these positions.

\subsection{Train speed}

The computed SPL spectra at S2 for speeds between 150 and $350 \mathrm{~km} / \mathrm{h}$ are displayed in Fig. 17. It is found that the SPL in the entire frequency range increases with the train speed. 


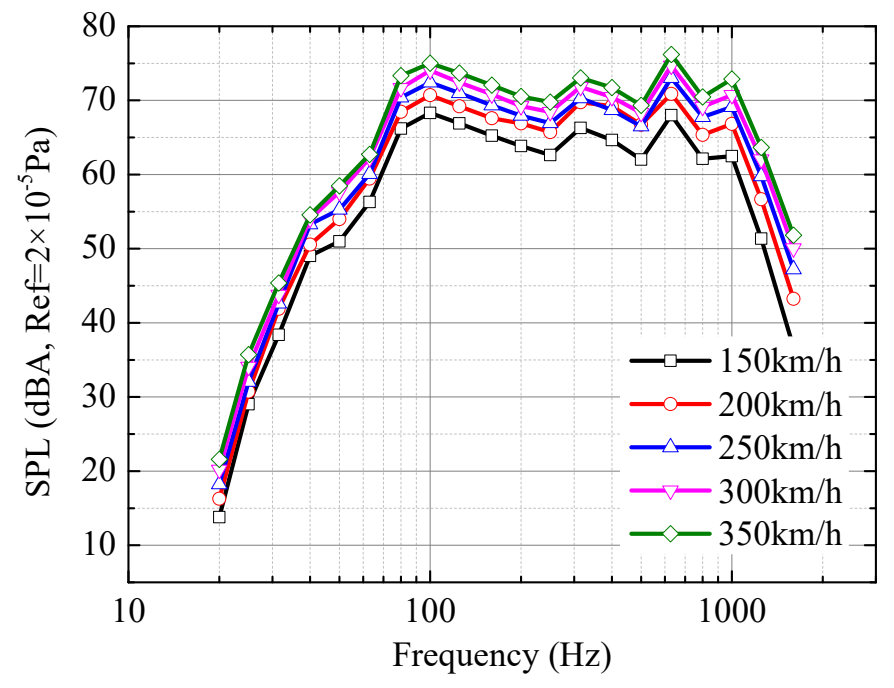

Fig. 17. SPL spectra of S2 at various speeds.

In the Chinese Technical Guidelines for Noise Impact Assessment [45], the speed correction of the SPL of railway wayside noise is given as

$$
C_{\mathrm{v}}=30 \lg \left(v / v_{0}\right)
$$

where $v$ denotes the train speed, and $v_{0}$ indicates the reference speed. This implies that the SPL increases by $9 \mathrm{~dB}$ if the speed doubles. The wayside noise of the elevated railway includes rolling noise, aerodynamic noise, and bridge-borne noise. Aerodynamic noise generally increases much more rapidly with speed than noise from mechanical sources, typically by $60 \lg (v)$ [46]. This section aims to obtain the relation between bridge-borne noise and train speed.

The overall predicted A-weighted SPLs at S1 and S2 are plotted against speed in Fig. 18. Linear fitting is utilized to obtain the relation between SPL and $\lg (v)$ with the least squares method to derive the fitting coefficient:

$$
C_{\mathrm{v}}=20 \lg \left(v / v_{0}\right)
$$

The coefficient of the right side of Eq. (34) was found as 19.78 (S1) and 19.59 (S2) but for conciseness, was rounded to 20 . 
(a)

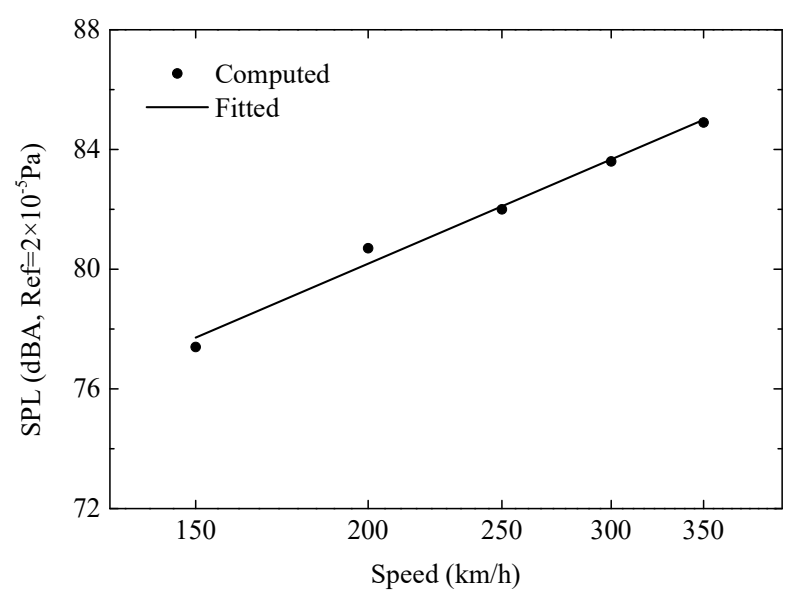

(b)

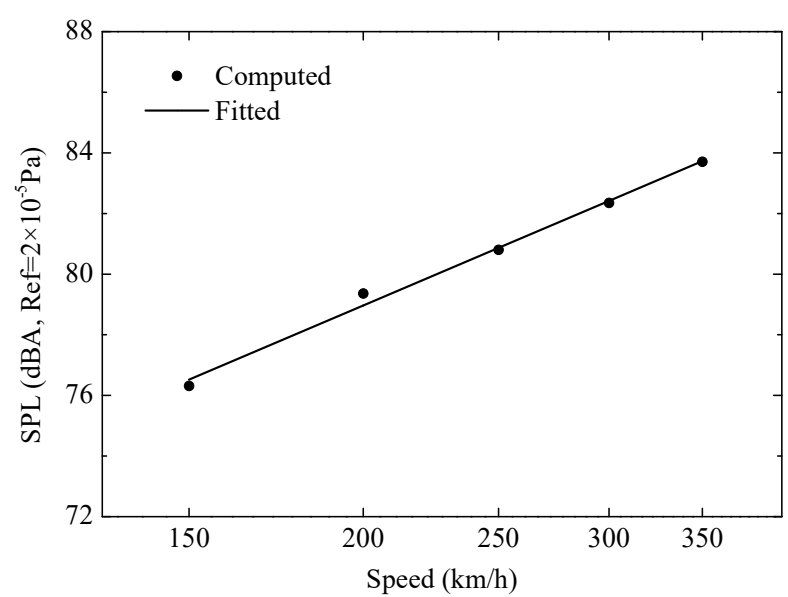

Fig. 18. Computed SPLs of bridge noise at various speeds: (a) S1; (b) S2.

\subsection{Geometrical attenuation}

The calculated SPLs obtained at 7.5, 15, 22.5, 30, 40, and $50 \mathrm{~m}$ from the centre of the westbound track for a train passing at $200 \mathrm{~km} / \mathrm{h}$ are shown in Fig. 19. The A-weighted SPL decreases with distance in the entire frequency range, e.g. the doubling of distance from $7.5 \mathrm{~m}$ to $15 \mathrm{~m}$ corresponds to a 3-dB decrease in SPL and the doubling of distance from $15 \mathrm{~m}$ to $30 \mathrm{~m}$ to a 4-dB decrease in SPL.

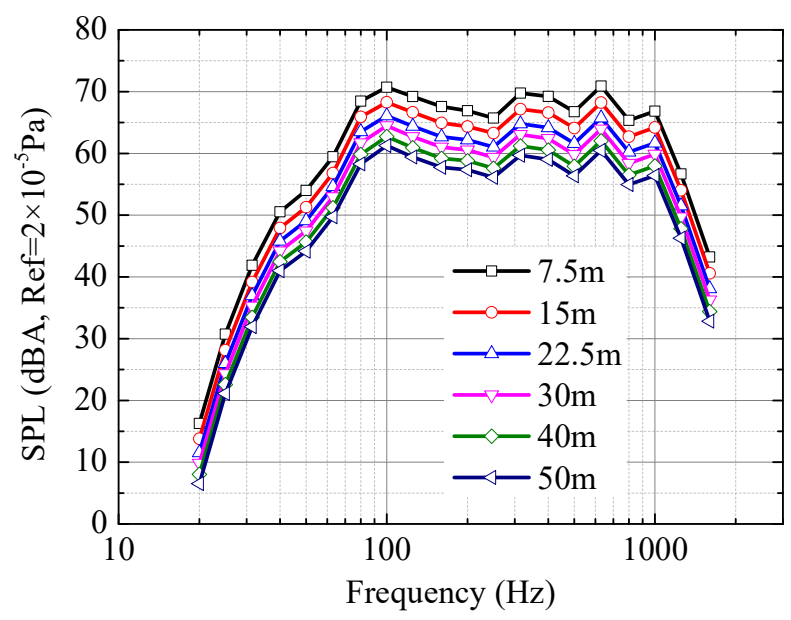

Fig. 19. SPL spectra computed at the speed of $200 \mathrm{~km} / \mathrm{h}$.

Generally, the expression for the geometrical attenuation of infinite line source is given as

$$
L(r)=L\left(r_{0}\right)-10 \lg \left(r / r_{0}\right)
$$

where $L(r)$ and $L\left(r_{0}\right)$ are the SPLs at the points where the distances to the source are $r$ and $r_{0}$, 
respectively. According to Eq. (35), doubling the distance to the source produces a SPL attenuation of $3 \mathrm{~dB}$.

In Technical Guidelines for Noise Impact Assessment [45], for a finite line source with the length of $l_{0}$, when $r<l_{0} / 3$ and $r_{0}<l_{0} / 3$,

$$
L(r)=L\left(r_{0}\right)-10 \lg \left(r / r_{0}\right)
$$

This implies that the finite line source can be regarded as approximately infinite in the near field.

When $l_{0} / 3<r<l_{0}$ and $l_{0} / 3<r_{0}<l_{0}$, Ref [45] recommends using

$$
L(r)=L\left(r_{0}\right)-15 \lg \left(r / r_{0}\right)
$$

This indicates that doubling the distance to the source produces a SPL attenuation of approximately $4.5 \mathrm{~dB}$.

When $r>l_{0}$ and $r_{0}>l_{0}$,

$$
L(r)=L\left(r_{0}\right)-20 \lg \left(r / r_{0}\right)
$$

This implies that, in the far field, a finite line source can be considered as a point, and doubling the distance to the source produces a SPL attenuation of approximately $6 \mathrm{~dB}$.

The above three equations are concise; however, they result in steep changes in gradient at the points $l_{0} / 3$ and $l_{0}$. It is difficult to predict the SPL using these equations if the unknown and reference points are from different regions. Therefore, it is indispensable to construct a unified formula to assess the SPL. A nonlinear fitting with the dimensionless variable $\lg \left(d / l_{0}\right)$ was applied to take account of the nonlinear propagation, as shown in Fig. 20.

$$
L(d)=L\left(d_{0}\right)+20.83 \lg \left(\frac{d_{0}}{d}\right)+5.84 \lg \left(\frac{d d_{0}}{l_{0}^{2}}\right) \lg \left(\frac{d_{0}}{d}\right)
$$

where $L(d)$ and $L\left(d_{0}\right)$ indicate the SPLs at the points where the horizontal distances to the track centreline are $d$ and $d_{0}$, respectively; $l_{0}$ is the full bridge length.

In the far field, the bridge can be regarded as a point source, and the SPL will be decreased by 6 $\mathrm{dB}$ when doubling the distance to the source. According to $L(d)-L(2 d) \leq 6 \mathrm{~dB}$, the valid distance of 
Eq. (39) is no more than $120 \mathrm{~m}$.

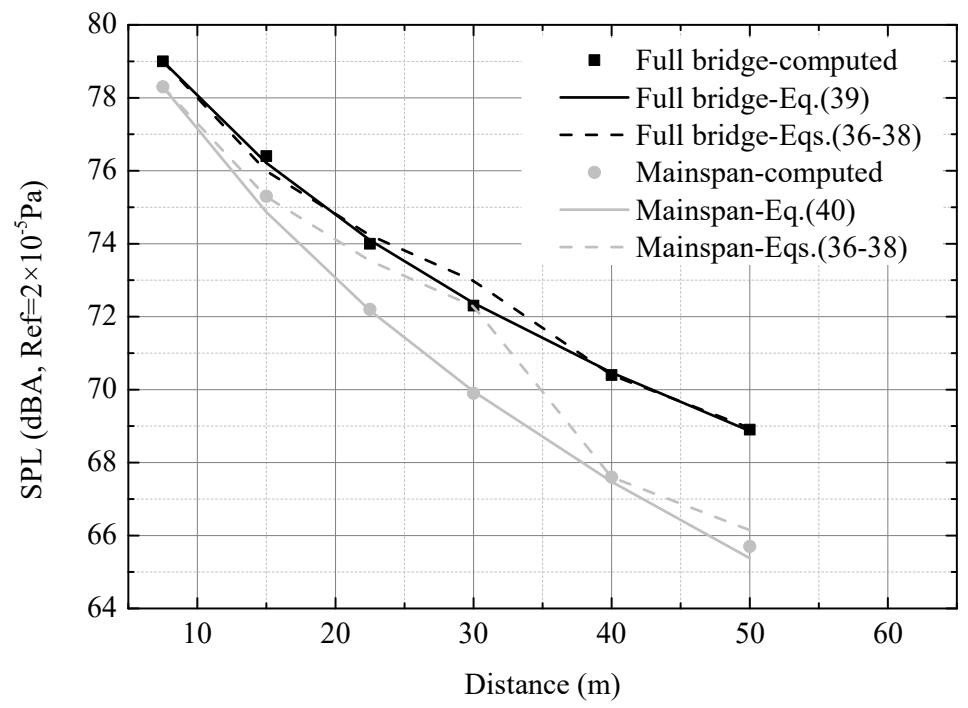

Fig. 20. Computed and fitted SPLs.

To investigate the bridge span effect on the noise prediction, the SPL radiated by the main span is also shown in Fig. 20. The fitted formula follows

$$
L^{\prime}(d)=L^{\prime}\left(d_{0}\right)+20.83 \lg \left(\frac{d_{0}}{d}\right)+5.84 \lg \left(\frac{d d_{0}}{l_{\mathrm{m}}^{2}}\right) \lg \left(\frac{d_{0}}{d}\right)
$$

where $L^{\prime}(d)$ and $L^{\prime}\left(d_{0}\right)$ indicate the SPLs at the points where the horizontal distances to the track centreline are $d$ and $d_{0}$, respectively; $l_{\mathrm{m}}$ is the main span length. From Fig. 20, as $30 \mathrm{~m}$ is near to $l_{0} / 3$, it produces an obvious error around the dividing distance applying Eqs. (36-38) to predict SPLs of the bridge. However, Eqs. (39-40) describe well the geometrical attenuation of the bridge noise in the valid distance range.

If an error of less than $1 \mathrm{~dB}\left(L(d)-L^{\prime}(d)<1 \mathrm{~dB}\right)$ is taken as the critical condition, it is required that $d<0.3 l_{\mathrm{m}}=12 \mathrm{~m}$, i.e. $d$ should be less than 0.3 times of the main span length. Therefore, it can be concluded that the adjacent spans can be ignored in deriving the structure-borne noise at the points that are less than $0.3 l_{\mathrm{m}}$ to the centre of the near track in the middle section of the main span. However, the proportion of the noise contributed by the adjacent spans will increase with the distance from the field point to the track centreline. At a distance $d$ of $50 \mathrm{~m}$ the error of ignoring adjacent spans will be more than $3 \mathrm{~dB}$. 


\section{Conclusions}

A hybrid FE-SEA method has been applied to study the vibration and noise of a composite railway bridge. FE is used to model the concrete deck and SEA to model the steel beam. Results are presented from field measurements of vibration and noise for such a composite bridge to validate this method. The main conclusions can be summarized as follows:

1) The vibration and noise of a composite bridge derived from the hybrid FE-SEA method agree well with the measured values.

2) The hybrid FE-SEA model has a good balance between accuracy and efficiency when computing the vibration and noise of composite structures with various modal densities.

3) The deck dominates the noise radiation below $125 \mathrm{~Hz}$, while the girder web radiates the most noise above $400 \mathrm{~Hz}$. In the middle frequency range between 125 and $400 \mathrm{~Hz}$, both the deck and girder have a significant contribution to the overall noise of the bridge.

4) The structure-borne noise radiated by the bridge generally increases with the train speed $v$ at a rate of approximately $20 \lg (v)$.

5) The adjacent spans can be ignored when calculating the structure-borne noise at points within a certain distance to the track centreline, but the proportion of the noise radiated from the adjacent spans will increase with the distance from the field point to the track centreline.

All data published in this paper are openly available from the University of Southampton repository at https://doi.org/10.5258/SOTON/D1202.

\section{Acknowledgements}

This work was supported by the National Natural Science Foundation of China (grant numbers 51608201, 51878277 and 51878565), the Jiangxi Provincial Department of Education (grant number GJJ 180295) and the China Scholarship Council.

\section{References}

[1] D.J. Thompson, Railway Noise and Vibration-Mechanisms, Modelling and Means of Control, 
Elsevier Ltd, Oxford, 2009.

[2] A.R. Crockett, J.R. Pyke, Viaduct design for minimization of direct and structure-radiated train noise, J. Sound Vib. 231 (2000) 883-897.

[3] T.X. Wu, J.H. Liu, Sound emission comparisons between the box-section and U-section concrete viaducts for elevated railway, Noise Control Eng. J. 60 (2012) 450-457.

[4] Q. Li, Y.L. Xu, D.J. Wu, Concrete bridge-borne low-frequency noise simulation based on train-track-bridge dynamic interaction, J. Sound Vib. 331 (2012) 2457-2470.

[5] X. Zhang, X.Z. Li, Q.M. Liu, J.F. Wu, Y.D. Li, Theoretical and experimental investigation on bridge-borne noise under moving high-speed train, Sci. China Technol. Sc. 56 (2013) 917-924.

[6] Q. Li, X.D. Song, D.J. Wu, A 2.5-dimensional method for the prediction of structure-borne low-frequency noise from concrete rail transit bridges, J. Acoust. Soc. Am. 135 (2014) 27182726.

[7] Q. Li, W.Q. Li, D.J. Wu, X.D. Song, A combined power flow and infinite element approach to the simulation of medium-frequency noise radiated from bridges and rails, J. Sound Vib. 365 (2016) 134-156.

[8] X.D. Song, D.J. Wu, Q. Li, D. Botteldooren, Structure-borne low-frequency noise from multi-span bridges: a prediction method and spatial distribution, J. Sound Vib. 367 (2016) 114128.

[9] X.D. Song, Q. Li, D.J. Wu, Prediction of rail and bridge noise in near- and far-field: a combined 2.5-dimensional and two-dimensional method, J. Vib. Acoust. 139 (2017) 11007.

[10]L.Z. Song, X.Z. Li, H. Hao, X. Zhang, Medium- and high-frequency vibration characteristics of a box-girder by the Waveguide Finite Element Method, Int J. Struct. Stab. Dy. 18 (2018) 1850141.

[11]J. Brozzetti, Design development of steel-concrete composite bridges in France, J. Constr. Steel Res. 55 (2000) 229-243.

[12]F. Augusztinovicz, F. Márki, K. Gulyás, A.B. Nagy, P. Fiala, P. Gajdátsy, Derivation of train track isolation requirement for a steel road bridge based on vibro-acoustic analyses, J. Sound Vib. 293 (2006) 953-964.

[13]K. Alten, R. Flesch, Finite element simulation prior to reconstruction of a steel railway bridge to reduce structure-borne noise, Eng. Struct. 35 (2012) 83-88.

[14]P.J. Remington, L.E. Wittig, Prediction of the effectiveness of noise control treatments in urban rail elevated structures, J. Acoust. Soc. Am. 78 (1985) 2017-2033.

[15]M.H.A. Janssens, D.J. Thompson, A calculation model for the noise from steel railway bridges, J. Sound Vib. 193 (1996) 295-305.

[16]O.G. Bewes, D.J. Thompson, C.J.C. Jones, A. Wang, Calculation of noise from railway bridges and viaducts: experimental validation of a rapid calculation model, J. Sound Vib. 293 (2006) 933-943.

[17]M.F. Harrison, D.J. Thompson, C.J.C. Jones, The calculation of noise from railway viaducts and bridges, Proc. Inst. Mech. Eng. Part F-J. Rail Rapid Transit 214 (2000) 125-134.

[18]F. Poisson, F. Margiocchi, The use of dynamic dampers on the rail to reduce the noise of steel railway bridges, J. Sound Vib. 293 (2006) 944-952.

[19]X.Z. Li, Q.M. Liu, S.L. Pei, L.Z. Song, X. Zhang, Structure-borne noise of railway composite bridge: numerical simulation and experimental validation, J. Sound Vib. 353 (2015) 378-394.

[20]N. Ouelaa, A. Rezaiguia, B. Laulagnet, Vibro-acoustic modelling of a railway bridge crossed by 
a train, Appl. Acoust. 67 (2006) 461-475.

[21]K. Michishita, Z. Yamaguchi, N. Nakajima, K. Sakagami, M. Morimoto, Numerical study on reduction of the elevated structure noise by surface absorption on plate girders, Appl. Acoust. 70 (2009) 1143-1147.

[22]X. Xie, D.Y. Wu, H. Zhang, Y. Shen, Y. Mikio, Low-frequency noise radiation from traffic-induced vibration of steel double-box girder bridge, J. Vib. Control 18 (2011) 373-384.

[23]R.S. Langley, P. Bremner, A hybrid method for the vibration analysis of complex structural-acoustic systems, J. Acoust. Soc. Am. 105 (1999) 1657-1671.

[24]D.J. Thompson, Wheel-rail noise generation, Part I: introduction and interaction model, J. Sound Vib. 161 (1993) 387-400.

[25]T.X. Wu, D.J. Thompson, On the rolling noise generation due to wheel/track parametric excitation, J. Sound Vib. 293 (2006) 566-574.

[26]X. Zhang, R. Liu, Z.Y. Cao, X.Y. Wang, X.Z. Li, Acoustic performance of a semi-closed noise barrier installed on a high-speed railway bridge: measurement and analysis considering actual service conditions, Measurement 138 (2019) 386-399.

[27]D.J. Thompson, E.L. Iglesias, X.W. Liu, J.Y. Zhu, Z.W. Hu, Recent developments in the prediction and control of aerodynamic noise from high-speed trains. International Journal of Rail Transportation 3 (2015) 119-150.

[28]T.X. Wu, D.J. Thompson, Behaviour of the normal contact force under multiple wheel/rail interaction, Veh. Syst. Dyn. 37 (2002) 157-174.

[29]L. Liang, X.Z. Li, J. Yin, D.X. Wang, W. Gao, Z. Guo, Vibration characteristics of damping pad floating slab on the long-span steel truss cable-stayed bridge in urban rail transit, Eng. Struct. 191 (2019) 92-103.

[30]K.L. Knothe, Z. Strzyzakowski, K. Willner, Rail vibrations in the high frequency range, J. Sound Vib. 169 (1994) 111-123.

[31]J.F. Hamet, Railway noise: use of the Timoshenko model in rail vibration studies, Acta Acust. United Acust. 85 (1999) 54-62.

[32]X.Y. Zhang, D.J. Thompson, Q. Li, D. Kostovasilis, M.G.R. Toward, G. Squicciarini, J. Ryue, A model of a discretely supported railway track based on a $2.5 \mathrm{D}$ finite element approach, $\mathrm{J}$. Sound Vib. 438 (2019) 153-174.

[33]X.Y. Lei, N. Noda, Analyses of dynamic response of vehicle and track coupling system with random irregularity of track vertical profile, J. Sound Vib. 258 (2002) 147-165.

[34]M.P. Norton, D.G. Karczub, Fundamentals of Noise and Vibration Analysis for Engineers, second ed., Cambridge University Press, Cambridge, 2003.

[35]D.A. Bies, C.H. Hansen, Engineering Noise Control: Theory and Practice, fourth ed., CRC Press, London, 2017.

[36]P.J. Shorter, R.S. Langley, On the reciprocity relationship between direct field radiation and diffuse reverberant loading, J. Acoust. Soc. Am. 117 (2005) 85-95.

[37]P.J. Shorter, R.S. Langley, Vibro-acoustic analysis of complex systems, J. Sound Vib. 288 (2005) 669-699.

[38]R.S. Langley, V. Cotoni, Response variance prediction for uncertain vibro-acoustic systems using a hybrid deterministic-statistical method, J. Acoust. Soc. Am. 122 (2007) 3445-3463.

[39]F.J. Fahy, P. Gardonio, Sound and Structural Vibration: Radiation, Transmission and Response, second ed., Academic Press, Oxford, 2007. 
[40]Q. Li, D.J. Thompson, M.G. Toward, Estimation of track parameters and wheel-rail combined roughness from rail vibration, Proc. Inst. Mech. Eng. Part F-J. Rail Rapid Transit 232 (2018) 1149-1167.

[41]H.L. Wei, Elevated track structure vibration and transmitting characteristics of urban mass transit, $\mathrm{PhD}$ dissertation of Tongji University, 2012.

[42] International Organization for Standardization, ISO 3095: 2005: Railway applicationsacoustics-measurement of noise emitted by rail bound vehicles, 2005.

[43]W. Zhai, K. Wang, C. Cai, Fundamentals of vehicle-track coupled dynamics, Vehicle Syst. Dyn. 47 (2009) 1349-1376.

[44]C.J.C. Jones, D.J. Thompson, R.J. Diehl, The use of decay rates to analyse the performance of railway track in rolling noise generation, J. Sound Vib. 293 (2006) 485-495.

[45]Ministry of Environmental Protection of the People's Republic of China, HJ 2.4-2009: Technical guidelines for noise impact assessment, 2009.

[46]C. Mellet, F. Létourneaux, F. Poisson, C. Talotte, High speed train noise emission: latest investigation of the aerodynamic/rolling noise contribution, J. Sound Vib. 293 (2006) 535-546. 